\title{
High-performance all-polymer solar cells based on fluorinated naphthalene diimide acceptor polymers with fine-tuned crystallinity and enhanced dielectric constants
}

Citation for published version (APA):

Xu, X., Li, Z., Wang, J., Lin, B., Ma, W., Xia, Y., Andersson, M. R., Janssen, R. A. J., \& Wang, E. (2018). Highperformance all-polymer solar cells based on fluorinated naphthalene diimide acceptor polymers with fine-tuned crystallinity and enhanced dielectric constants. Nano Energy, 45, 368-379.

https://doi.org/10.1016/j.nanoen.2018.01.012

Document license:

TAVERNE

DOI:

10.1016/j.nanoen.2018.01.012

Document status and date:

Published: 01/03/2018

Document Version:

Publisher's PDF, also known as Version of Record (includes final page, issue and volume numbers)

\section{Please check the document version of this publication:}

- A submitted manuscript is the version of the article upon submission and before peer-review. There can be important differences between the submitted version and the official published version of record. People interested in the research are advised to contact the author for the final version of the publication, or visit the DOI to the publisher's website.

- The final author version and the galley proof are versions of the publication after peer review.

- The final published version features the final layout of the paper including the volume, issue and page numbers.

Link to publication

\footnotetext{
General rights

- You may freely distribute the URL identifying the publication in the public portal. follow below link for the End User Agreement:

www.tue.nl/taverne

\section{Take down policy}

If you believe that this document breaches copyright please contact us at:

openaccess@tue.nl

providing details and we will investigate your claim.
}

Copyright and moral rights for the publications made accessible in the public portal are retained by the authors and/or other copyright owners and it is a condition of accessing publications that users recognise and abide by the legal requirements associated with these rights.

- Users may download and print one copy of any publication from the public portal for the purpose of private study or research.

- You may not further distribute the material or use it for any profit-making activity or commercial gain

If the publication is distributed under the terms of Article $25 \mathrm{fa}$ of the Dutch Copyright Act, indicated by the "Taverne" license above, please 
Full paper

\title{
High-performance all-polymer solar cells based on fluorinated naphthalene diimide acceptor polymers with fine-tuned crystallinity and enhanced dielectric constants
}

\author{
Xiaofeng $\mathrm{Xu}^{\mathrm{a}, 1}$, Zhaojun $\mathrm{Li}^{\mathrm{a}, 1}$, Junke Wang ${ }^{\mathrm{b}}$, Baojun $\mathrm{Lin}^{\mathrm{c}}$, Wei $\mathrm{Ma}^{\mathrm{c}}$, Yangjun $\mathrm{Xia}^{\mathrm{d}, *}$, \\ Mats R. Andersson ${ }^{\mathrm{e}}$, René A.J. Janssen ${ }^{\mathrm{b}, *}$, Ergang Wang ${ }^{\mathrm{a}, *}$ \\ ${ }^{a}$ Department of Chemistry and Chemical Engineering/Applied Chemistry, Chalmers University of Technology, SE-412 96 Göteborg, Sweden \\ ${ }^{\mathrm{b}}$ Molecular Materials and Nanosystems and Institute for Complex Molecular Systems, Eindhoven University of Technology, PO BOX 513, 5600 MB Eindhoven, The \\ Netherlands \\ ' State Key Laboratory for Mechanical Behavior of Materials, Xi'an Jiaotong University, Xi'an 710049, China \\ d Key Laboratory of Optoelectronic Technology and Intelligent Control of Ministry Education, Lanzhou Jiaotong University, Lanzhou 730070, China \\ ${ }^{\mathrm{e}}$ Flinders Centre for Nanoscale Science and Technology, Flinders University, Sturt Road, Bedford Park, Adelaide, SA 5042, Australia
}

\section{A R T I C L E I N F O}

\section{Keywords:}

All-polymer solar cells

Acceptor polymers

Binding energy

Dielectric constants

Organic photovoltaics

\begin{abstract}
A B S T R A C T
Growing interests have been devoted to the synthesis of polymer acceptors as alternatives to fullerene derivatives to realize high-performance and stable all-polymer solar cells (all-PSCs). So far, one of the key factors that limit the performance of all-PSCs is low photocurrent density (normally $<14 \mathrm{~mA} / \mathrm{cm}^{2}$ ). One potential solution is to improve the dielectric constants $\left(\varepsilon_{\mathrm{r}}\right)$ of polyme $\mathrm{r}_{\mathrm{r}}$ :polymer blends, which tend to reduce the binding energy of excitons, thus boosting the exciton dissociation efficiencies. Nevertheless, the correlation between $\varepsilon_{\mathrm{r}}$ and photovoltaic performance has been rarely investigated for all-PSCs. In this work, five fluorinated naphthalene diimide (NDI)-based acceptor polymers, with different content of fluorine were synthesized. The incorporation of fluorine increased the $\varepsilon_{\mathrm{r}}$ of the acceptor polymers and blend films, which improved the charge generation and overall photocurrent of the all-PSCs. As a result, the PTB7-Th:PNDI-FT10 all-PSC attained a high power conversion efficiency (PCE) of 7.3\% with a photocurrent density of $14.7 \mathrm{~mA} / \mathrm{cm}^{2}$, which surpassed the values reported for the all-PSC based on the non-fluorinated acceptor PNDI-T10. Interestingly, similarly high photovoltaic performance was maintained regardless of a large variation of donor:acceptor ratios, which revealed the good morphological tolerance and the potential for robust production capability of all-PSCs.
\end{abstract}

\section{Introduction}

Organic photovoltaic (OPV) devices are promising candidates for solar energy conversion technology due to their potential to provide low cost, large-area and flexible solar panels with relatively short energy payback time $[1,2]$. In the past few years, OPV devices based on bulk-heterojunction (BHJ) active layers achieved power conversion efficiencies (PCEs) exceeding 13\% [3-6]. The donor materials were mainly based on conjugated polymers or small molecules, and the most commonly used acceptor materials were fullerene derivatives (e.g. PCBM). However, extensive research revealed that fullerene derivatives have serious drawbacks [7-9]. Driven by the need to develop alternative acceptor materials, all-polymer solar cells (all-PSCs), containing BHJ active layers based on conjugated polymers as both electron-donor
(D) and electron-acceptor (A), have drawn tremendous attention in the last five years [10-12]. All-PSCs feature intrinsic advantages such as potentially low synthetic cost, tunable band gaps to realize complementary absorption spectra which enhance light harvesting, appropriate energy levels to maximize open-circuit voltage $\left(V_{\text {oc }}\right)$ [13], good morphological stability [14] as well as robust mechanical properties [15]. Growing efforts to synthesize new acceptor polymers [16-25], led to the improvement of the PCEs of all-PSCs from 3\% to $10 \%$ within the past five years [13,26-33]. Nevertheless, the performance of all-PSCs still lags behind the state-of-the-art polymer:PCBM solar cells [34]. Although relatively high $V_{\mathrm{oc}}>1.1 \mathrm{~V}$ [13] and fill factor (FF) $>0.7$ $[23,27,29]$ have been achieved for all-PSCs, their performance is constrained because the short-circuit current densities $\left(J_{\mathrm{sc}}\right)$ remain generally lower than those of the PCBM-based PSCs $[3,35,36]$. Despite the

\footnotetext{
* Corresponding authors.

E-mail addresses: yjxia73@126.com (Y. Xia),r.a.j.janssen@tue.nl (R.A.J. Janssen), ergang@chalmers.se (E. Wang).

${ }^{1}$ These authors contributed equally to this work.
} 
fact that all-PSCs have the advantages of incorporating donor and acceptor polymers with complementary absorption spectra [14,27], low absorption coefficients and imperfect exciton dissociation of naphthalene diimide (NDI)-based acceptor polymers still limit the improvement in $J_{\text {sc }}$ [24].

Relative dielectric constants $\left(\varepsilon_{\mathrm{r}}\right)$ of photovoltaic materials can play a critical role on the performance of PSCs [37]. Compared to inorganic semiconductors with $\varepsilon_{\mathrm{r}}$ in the range of 10-16, conjugated polymers generally feature much lower $\varepsilon_{\mathrm{r}}$ in the range of 3-6. PCBM also shows low $\varepsilon_{\mathrm{r}}$ of around 4 [38]. Thus, the $\varepsilon_{\mathrm{r}}$ of polymer:PCBM blend films usually fall in the range of 4-8 $[38,39]$. Owing to the low $\varepsilon_{\mathrm{r}}$ of organic photovoltaic materials, a charge transfer (CT) state is believed to appear upon photoexcitation, where excitons are formed as bound hole and electron pairs with high binding energy in the order of $100 \mathrm{meV}$ [37]. It has been suggested that increasing the $\varepsilon_{\mathrm{r}}$ of organic semiconductors can reduce the exciton binding energy and lead to more efficient exciton dissociation, thereby boosting $J_{\mathrm{sc}}$ and PCEs of PSCs [37]. So far, a few molecular design approaches have been applied to improve $\varepsilon_{\mathrm{r}}$ of conjugated materials. One is to attach highly polar substituents (cyano groups or oligoethylene glycol side chains) on conjugated materials or fullerene derivatives [40-42]. Very recently, Kim et al. developed a new class of acceptor polymers incorporating polar electron-withdrawing cyanovinylene groups on NDI units. The acceptor polymers promoted the exciton dissociation and electron transport, leading to a high PCE of $7.4 \%$ in all-PSCs [43]. Incorporation of fluorine atoms on polymer backbones has also been used as another method to enhance $\varepsilon_{\mathrm{r}}[44,45]$. The dipole moments associated with C-F bonds may impart net dipole moments to the polymers, thereby increasing $\varepsilon_{\mathrm{r}}$ [46]. Luscombe et al. reported a fluorinated quinoxaline-based polymer which attained a record-breaking $\varepsilon_{\mathrm{r}}$ of 7.9, but the PCBM-based PSCs gave a moderate PCE of 4\% [39]. On the other hand, some high-performing donor polymers such as PTB7 and PCDTBT only presented low $\varepsilon_{\mathrm{r}}$ of around 3 [38]. It is still puzzling to directly correlate the device performance of solar cells with the structural modulations of the materials and the resulting $\varepsilon_{\mathrm{r}}$, because the device parameters are also strongly influenced by other factors such as absorption coefficients, film morphology, energy offsets, and mobilities in the active layers. Only few studies have been performed on the correlation between the $\varepsilon_{\mathrm{r}}$ of polymers and the photovoltaic performance of polymer:PCBM solar cells [38,40,47-50]. Especially, there is a dearth of investigation on how the $\varepsilon_{\mathrm{r}}$ of acceptor polymers could influence the performance of all-PSCs.

In order to improve the $\varepsilon_{\mathrm{r}}$ of polymer:polymer blends and study the influence of $\varepsilon_{\mathrm{r}}$ on device parameters, exciton dissociation and recombination losses of all-PSCs, we synthesized five fluorinated NDIbased acceptor polymers (F-N2200, PNDI-FTx and PNDI-F45T10) (Scheme 1). We performed a detailed comparison between the nonfluorinated acceptor polymers N2200 [51] and PNDI-T10 [23], and the corresponding fluorinated acceptor polymers. The high-performing polymer poly[4,8-bis[5-(2-ethylhexyl)-2-thienyl]benzo[1,2-b:4,5-b']dithiophene-alt-(4-(2-ethylhexyl)-3-fluorothieno[3,4-b]thiophene)-2-carboxylate-2,6-diyl]] (PTB7-Th) was used as donor in this study. We found that the fluorinated polymers and the corresponding blend films presented higher $\varepsilon_{\mathrm{r}}$ compared to the non-fluorinated counterparts. The all-PSC based on the fluorinated acceptor PNDI-FT10 attained a high FF of 0.68 and a high PCE of 7.3\%. It gave one of the highest $J_{\mathrm{sc}}(14.7 \mathrm{~mA}$ / $\mathrm{cm}^{2}$ ) among all-PSCs, which is $14 \%$ higher than that of the all-PSCs based on the non-fluorinated PNDI-T10. Interestingly, the PTB7Th:PNDI-FT10 all-PSCs could retain relatively high photovoltaic performance with a large variation of D:A ratios, indicating good morphological tolerance in this system, which is rarely observed in all-PSCs.

\section{Results and discussion}

\subsection{Polymer synthesis}

The synthetic routes of the fluorinated acceptor polymers are depicted in Scheme S1. The alternating poly[[ $N, N$-bis(2-octyldodecyl)naphthalene-1,4,5,8-bis(dicarboximide)-2,6-diyl]-alt-(3,3'-difluoro-

2,2'-bithiophene)-5,5'-diyl] (F-N2200) was prepared by the Stille coupling reaction among the monomers 2,6-dibromonaphthalene-1,4,5,8tetracarboxylic- $N, N$-bis(2-octyldodecyl)diimide $\left(\mathrm{NDIBr}_{2}\right)$ and $\left(3,3^{\prime}\right.$-difluoro-(2,2'-bithiophene)-5,5'-diyl)bis(trimethylstannane) (F-2T) [16]. Motivated by our previous work [23], different amounts of thiophene (T) units were introduced into the backbone of F-N2200 to afford a series of random copolymers PNDI-FTx (x stands for the percentage of the thiophene units relative to the total donor units). Polymer PNDIF45T10 was synthesized by incorporating $10 \%$ of thiophene units and equal amounts (45\%) of bithiophene (2T) and fluorinated bithiophene (F-2T) units in the backbone. The five polymers exhibited good solubility in chlorobenzene (CB) and $o$-dichlorobenzene $(o \mathrm{DCB})$ at room temperature.

Molecular weights were measured via gel permeation chromatography (GPC) in 1,2,4-trichlorobenzene at $150^{\circ} \mathrm{C}$. As summarized in Table 1, F-N2200 showed the lowest number-average molecular weight $\left(M_{\mathrm{n}}\right)$ of $51.6 \mathrm{kDa}$. Similar to our previous report, the random copolymers tended to have higher molecular weights [23]. By increasing the content of thiophene units, the $M_{\mathrm{n}}$ of PNDI-FTx were gradually improved from $58.6 \mathrm{kDa}$ for PNDI-FT10 to $84.7 \mathrm{kDa}$ for PNDI-FT50. The increased $M_{\mathrm{n}}$ can be attributed to the more disordered backbones and improved solubility of the random copolymers. Polydispersity indices (PDIs) of around 2.0 were calculated for the five fluorinated acceptor polymers. Thermogravimetric analysis (TGA) of all five polymers revealed high thermal stability with decomposition temperature over $400{ }^{\circ} \mathrm{C}$ (Fig S1). Unlike the non-fluorinated PNDI-Tx polymers, which exhibited clear melting and crystallization transitions in the differential scanning calorimetry (DSC) measurements [23], none of the fluorinated polymers presented detectable thermal transitions in the temperature range of $0-320^{\circ} \mathrm{C}$ (Fig S2).

\subsection{Optical and electrochemical properties}

The absorption spectra of the donor and acceptor polymers were measured via UV-Vis-NIR absorption spectroscopy. As depicted in Fig. 1a and b, all acceptor polymers featured two distinct absorption bands at $350-450 \mathrm{~nm}$ and $450-850 \mathrm{~nm}$, which stem from the excitations with the $\pi-\pi^{*}$ manifolds and correspond to the transitions with local (NDI) and intramolecular charge transfer (ICT) character, respectively [23]. Owing to the enhanced $\pi-\pi$ stacking and intermolecular interactions in the solid state, red-shifted absorption spectra were found for all the polymers as compared to the spectra in solution. Both in solution and films, the donor polymer PTB7-Th presented much higher absorption coefficients than those of the acceptor polymers, indicating that PTB7-Th had the predominant absorption contribution in these donor:acceptor blends. The blend films exhibited absorption coefficients of around $5.0 \times 10^{4}-5.3 \times 10^{4} \mathrm{~cm}^{-1}$ at $693 \mathrm{~nm}$ (Fig. 1c). It was noticed that the blend films based on the fluorinated F-N2200 and PNDI-FT10 displayed slightly higher absorption coefficients than the blends based on the non-fluorinated N2200 and PNDI-T10, although the fluorinated polymers showed slightly blue-shifted absorption spectra. In addition, temperature-dependent absorbance measurements were performed to study the aggregation behavior of the polymers in solution (Fig S3). PTB7-Th, N2200 and F-N2200 showed large decreases in the long wavelength absorption maximum, and blue-shifted absorption edges during the warming process from $20{ }^{\circ} \mathrm{C}$ to $100{ }^{\circ} \mathrm{C}$. This indicated that these polymers formed strong aggregates in solution at room temperature, which were gradually disaggregated at higher temperature. In contrast, reduced aggregation was observed in the solution of all random copolymers, since smaller changes in the absorption profiles were found, where the absorption shoulders gradually declined and finally disappeared at high temperature. Especially, PNDI-FT50 with the most disordered backbones showed nearly the same absorption profiles during the warming process from $20^{\circ} \mathrm{C}$ to $100{ }^{\circ} \mathrm{C}$, implying 


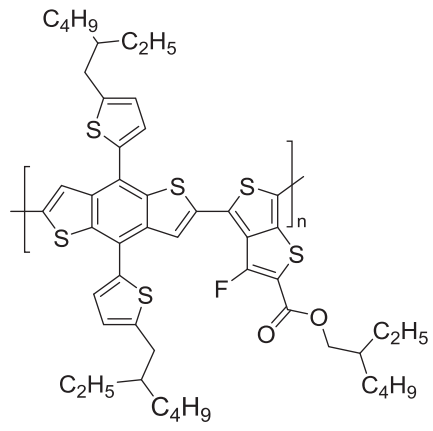

PTB7-Th

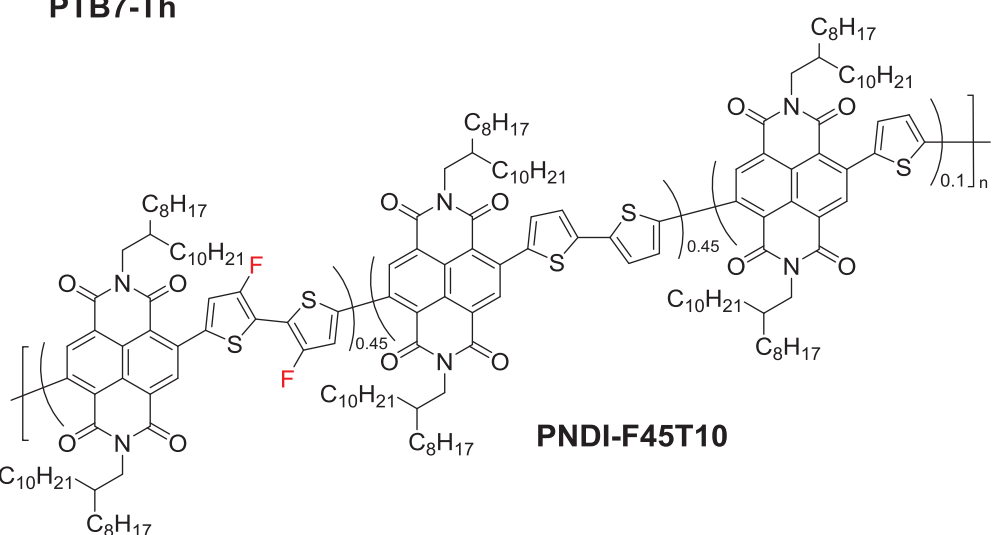

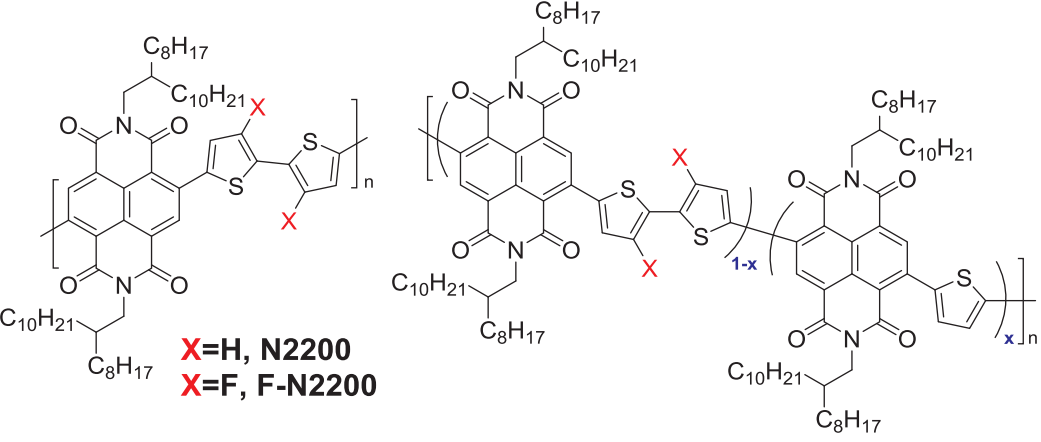

$X=H, x=0.1$, PNDI-T10 $X=F, x=0.1$, PNDI-FT10 $X=F, x=0.2$, PNDI-FT20 $X=F, x=0.5$, PNDI-FT50

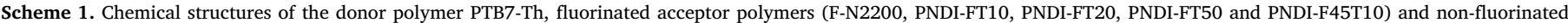
acceptor polymers (N2200 and PNDI-T10).

Table 1

Molecular weights and optical properties of polymers.

\begin{tabular}{lllll}
\hline Polymer & $M_{\mathrm{n}}(\mathrm{kDa})$ & PDI & $\lambda_{\max }{ }^{\mathrm{a}}(\mathrm{nm})$ & $E_{\mathrm{g}}(\mathrm{eV})$ \\
\hline PTB7-Th & 35.0 & 3.0 & 700 & 1.60 \\
N2200 [23] & 30.5 & 3.8 & 698 & 1.44 \\
PNDI-T10 & 41.9 & 2.8 & 694 & 1.55 \\
F-N2200 & 51.6 & 1.9 & 684 & 1.55 \\
PNDI-FT10 & 58.6 & 2.2 & 679 & 1.57 \\
PNDI-FT20 & 78.8 & 2.2 & 648 & 1.58 \\
PNDI-FT50 & 84.7 & 2.1 & 626 & 1.60 \\
PNDI-F45T10 & 79.1 & 2.3 & 677 & 1.53 \\
\hline
\end{tabular}

${ }^{a}$ Absorption peak in the thin film.

limited aggregation in the solution. The optical band gaps $\left(E_{\mathrm{g}}\right)$ of the acceptor polymers were around $1.53-1.60 \mathrm{eV}$, which were determined from the absorption onsets of the thin films (Table 1).

As energy levels of conjugated polymers are vital for determining $V_{\text {oc }}$ of all-PSCs, the highest occupied molecular orbital (HOMO) levels and the lowest unoccupied molecular orbital (LUMO) levels were evaluated by using square wave voltammetry (SWV) measurements (Fig S4). As depicted in the energy level diagram (Fig. 1d), the fluorinated polymers exhibited low-lying LUMO levels compared to the corresponding non-fluorinated polymers, which can be attributed to the strong electron-withdrawing property of fluorine [52]. Since the $V_{\text {oc }}$ of a solar cell is roughly linear to the offsets between the HOMO level of donor and the LUMO level of acceptor, a lower $V_{\text {oc }}$ is expected to be obtained from the all-PSCs based on the fluorinated acceptor polymers. We also found that the LUMO levels of the fluorinated polymers were gradually up-shifted with the decrease in the content of the F-2T units. This trend agrees well with the previous observation in literature [53]. On the other hand, the HOMO levels of the acceptor polymers stayed around $-6.40 \mathrm{eV}$ with only small variations.

\subsection{Photovoltaic properties}

Both conventional and inverted all-PSCs were fabricated to evaluate the photovoltaic performance of the acceptor polymers. Our previous report revealed that the conventional all-PSCs fabricated from PTB7Th:N2200 and PTB7-Th:PNDI-T10 exhibited superior performance compared to the inverted devices [23]. In contrast, this work presented that the fluorinated acceptor polymers performed better in the inverted all-PSCs as compared to the conventional devices (Figs S5a and S5b). One of the reasons may stem from the different vertical phase separation induced by the reduced surface tension of fluorinated acceptor polymers, where the lower surface tension may promote acceptor polymers move toward the ITO cathode, and improve the electron extraction in inverted devices $[18,54,55]$. Fig. 2a shows the current density-voltage $(J-V)$ curves of the inverted all-PSCs with the device configuration of ITO/ZnO $(40 \mathrm{~nm}) /$ active layer/ $\mathrm{MoO}_{3}(10 \mathrm{~nm}) / \mathrm{Ag}$ $(100 \mathrm{~nm})$ under an illumination of AM 1.5G simulated solar light at $100 \mathrm{~mW} / \mathrm{cm}^{2}$. The device parameters (active layer thickness, $V_{\mathrm{oc}}, J_{\mathrm{sc}}, \mathrm{FF}$ and PCEs) are summarized in Table 2. The variations of $V_{\text {oc }}$ of the allPSCs based on different acceptor polymers can be well explained by the changes of the LUMO levels of the acceptor polymers as discussed in the electrochemical section (Fig. 1d). Both the F-N2200- and PNDI-FT10based all-PSCs exhibited $0.09 \mathrm{~V}$ lower $V_{\text {oc }}$, compared to the corresponding non-fluorinated N2200- and PNDI-T10-based all-PSCs, respectively. On the other hand, the improved $J_{\mathrm{sc}}$ of $12.9 \mathrm{~mA} / \mathrm{cm}^{2}$ and FF of 0.58 resulted in a higher PCE of $5.4 \%$ for the F-N2200-based all-PSCs as compared to the non-fluorinated analogue. Similarly, the all-PSCs based on the fluorinated random copolymer PNDI-FT10 (D:A ratio = 1:1 and 2.5:1) also achieved enhanced $J_{\mathrm{sc}}$ at the expense of $V_{\mathrm{oc}}$ as compared with the all-PSC based on the non-fluorinated polymer PNDI$\mathrm{T} 10$.

Motivated by our previous work, thermal annealing (TA) and solvent annealing (SA) of the active layers were employed to optimize the morphology and improve the performance of the all-PSCs [23]. We noticed that TA at $80^{\circ} \mathrm{C}$ for $5 \mathrm{~min}$ can improve the device performance 

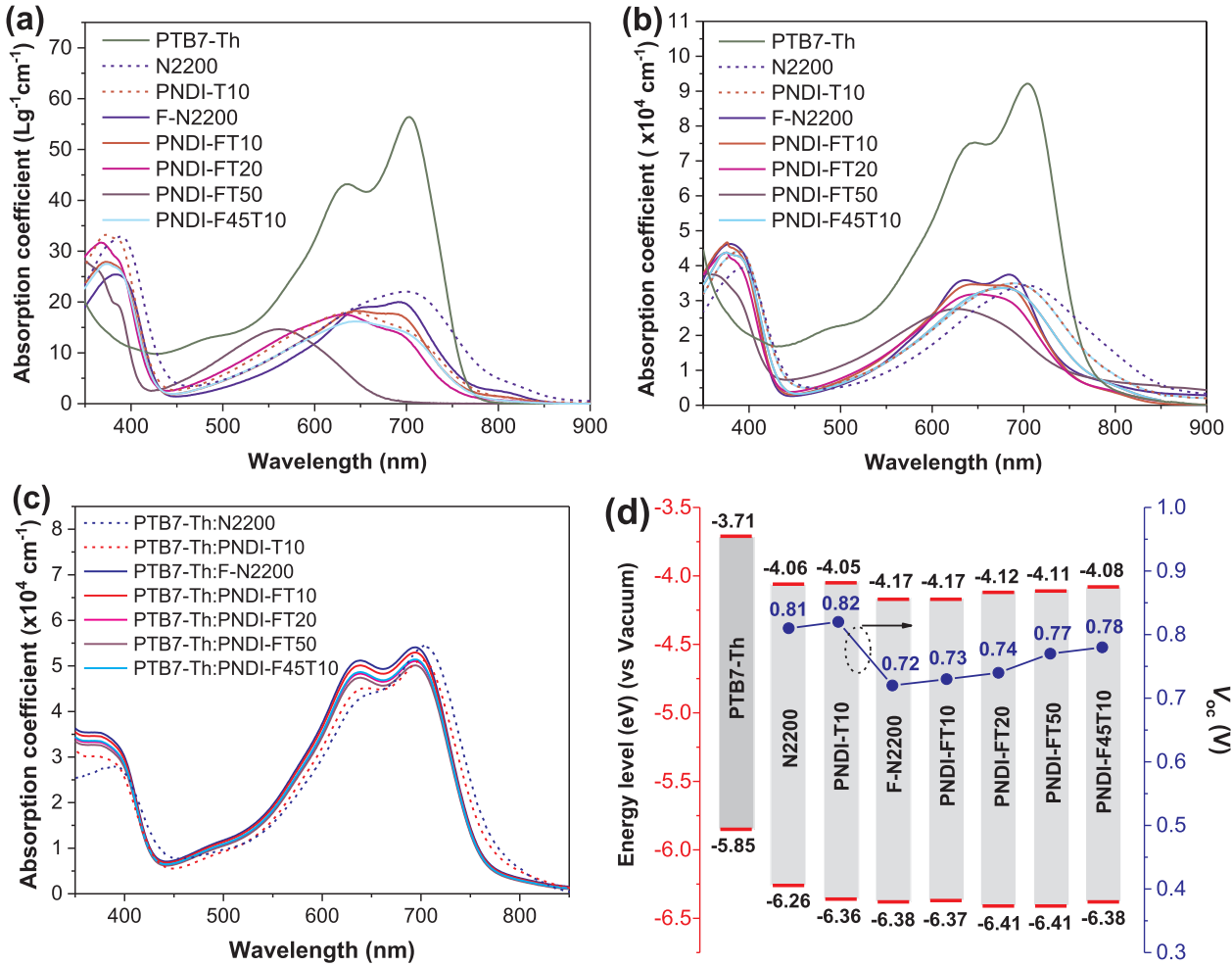

Fig. 1. (a) Absorption coefficients of the polymers in $o$ DCB solution. (b) Absorption coefficients of the polymers in thin films. (c) Absorption coefficients of the blend films (w/w = 1:1) (d) Energy level diagram of the polymers and the corresponding $V_{\text {oc }}$ of the all-PSCs. of the PTB7-Th:PNDI-FT10 all-PSCs from $5.0 \%$ to $6.1 \%$, but further extending TA time or increasing TA temperature led to lower performance (Table S1). Upon SA with $o$ DCB for $1.5 \mathrm{~h}$, nearly the same $V_{\text {oc }}$ and $J_{\text {sc }}$, but clearly enhanced FF were observed in the PTB7-Th:PNDIFT10 all-PSCs with two D:A ratios of $1: 1$ and $2.5: 1$, which led to the enhanced PCEs of $7.2 \%$ and 7.3\%, respectively. The PTB7-Th:PNDI-T10 all-PSC showed a slightly lower PCE of $6.9 \%$ compared to our previous report, mainly due to the lower $M_{\mathrm{n}}$ of PNDI-T10 used in this work [23]. It is worth noting that the $J_{\mathrm{sc}}$ of $14.7 \mathrm{~mA} / \mathrm{cm}^{2}$ is one of the highest values recorded for all-PSCs to date. Interestingly, the two all-PSCs based on the fluorinated acceptors F-N2200 and PNDI-FT10 afforded clearly higher $J_{\mathrm{sc}}$ as compared to the corresponding non-fluorinated acceptors N2200 and PNDI-T10. To understand the reasons behind, we decided to investigate the film morphology, $\varepsilon_{\mathrm{r}}$, binding energy, quenching efficiency and recombination losses in the next sections. In addition, a preliminary stability test was performed in this work. Undesired fast decay in PCEs was recorded from the inverted PTB7Th:PNDI-FT10 all-PSC when it was stored at $20^{\circ} \mathrm{C}$ in an inert atmosphere (Table S2).

Generally, D:A ratios can largely influence the performance of polymer:PCBM solar cells, where the best performance can be achieved for a certain D:A ratio or with only small variations. In this work, we studied the influence of variations in D:A ratios on the photovoltaic performance of all-PSCs. To this end, PTB7-Th:PNDI-FT10 all-PSCs with large variations in the D:A ratios from 6:1 to 1:2 were fabricated in this work. The photovoltaic parameters of the all-PSCs are depicted in Fig. 3 and Fig S5c. When the D:A ratios were varied from 6:1 to $1: 2$, the $V_{\mathrm{oc}}$ had almost no differences with values remaining around $0.73 \mathrm{~V}$. Decent $J_{\text {sc }}$ over $13 \mathrm{~mA} / \mathrm{cm}^{2}$ and FF above 0.5 can be maintained for the D:A ratios from $4: 1$ to $1: 1.3$, leading to PCEs over $5 \%$. The best performing devices exhibited high PCEs over 7\% and were achieved for two D:A ratios of 2.5:1 and 1:1. Surprisingly, even at the extreme D:A ratio of $6: 1$, the all-PSC still retained a decent PCE of $4.3 \%$, implying an efficient exciton diffusion, charge generation and charge transport in this system. Several studies aimed at reducing the content of PCBM in polymer:PCBM solar cells revealed that the photovoltaic performance was not very sensitive for large variations in D:A ratios [56-59]. However, none of the all-PSCs have shown this property with high PCEs over $4 \%$ [60]. Our finding grants one more advantage for all-PSCs in mass production, since precise control of D:A ratios is not required in this system.

The external quantum efficiencies (EQEs) were measured to
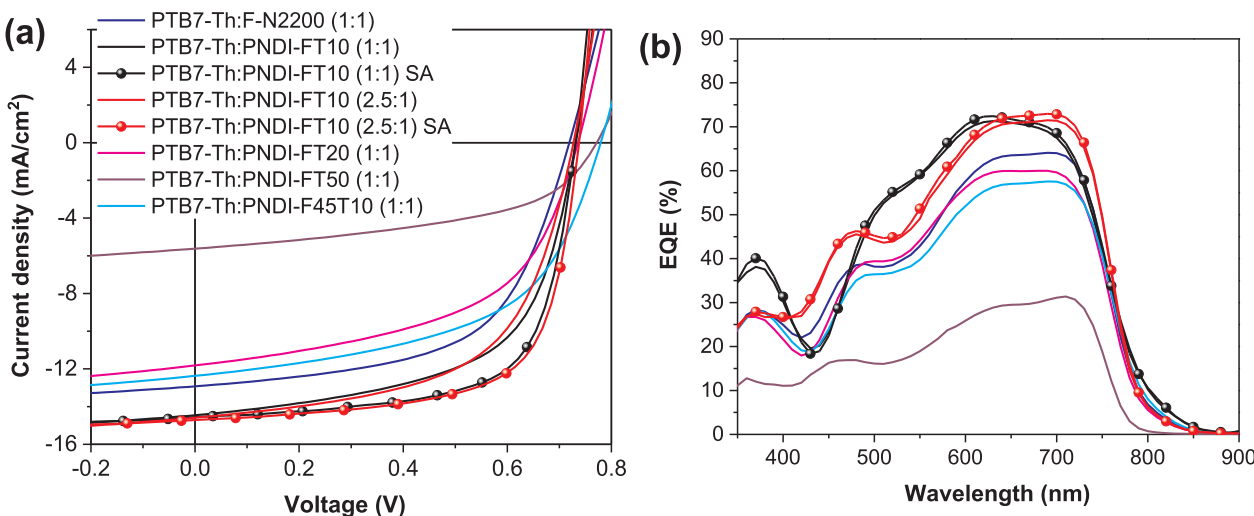

Fig. 2. (a) $J-V$ characteristics and (b) the corresponding EQE spectra of the inverted all-PSCs. 
Table 2

Photovoltaic parameters of the optimized all-PSCs. ${ }^{\mathrm{a}}$

\begin{tabular}{|c|c|c|c|c|c|}
\hline Donor:acceptor & Film thickness [nm] & $V_{\mathrm{oc}}[\mathrm{V}]$ & $J_{\mathrm{sc}}\left[\mathrm{mA} / \mathrm{cm}^{2}\right]$ & $\mathrm{FF}$ & PCE [\%] \\
\hline PTB7-Th:N2200 $(1: 1)^{\mathrm{a}}$ & 90 & 0.81 & $9.4(8.7)^{\mathrm{d}}$ & 0.49 & $3.7[23]$ \\
\hline PTB7-Th:PNDI-T10 $(1: 1)^{\mathrm{a}} \mathrm{SA}^{\mathrm{c}}$ & 90 & 0.82 & $12.9(12.1)$ & 0.65 & 6.9 \\
\hline PTB7-Th:F-N2200 (1:1) & 90 & 0.72 & $12.9(12.3)$ & 0.58 & 5.4 \\
\hline PTB7-Th:PNDI-FT10 (1:1) ${ }^{\mathrm{b}}$ & 95 & 0.73 & $14.4(14.2)$ & 0.60 & 6.3 \\
\hline PTB7-Th:PNDI-FT10 $(1: 1)^{\mathrm{b}} \mathrm{SA}^{\mathrm{c}}$ & 95 & 0.73 & $14.6(14.4)$ & 0.68 & $7.2(6.9)^{\mathrm{e}}$ \\
\hline PTB7-Th:PNDI-FT10 (2.5:1) ${ }^{\mathrm{b}}$ & 95 & 0.73 & $14.5(14.0)$ & 0.59 & 6.2 \\
\hline PTB7-Th:PNDI-FT10 $(2.5: 1)^{\mathrm{b}} \mathrm{SA}^{\mathrm{c}}$ & 95 & 0.74 & $14.7(14.3)$ & 0.67 & $7.3(6.9)^{\mathrm{e}}$ \\
\hline PTB7-Th:PNDI-FT20 (1:1) ${ }^{\mathrm{b}}$ & 90 & 0.74 & $11.8(11.8)$ & 0.53 & 4.6 \\
\hline PTB7-Th:PNDI-FT50 (1:1) & 85 & 0.77 & $5.6(5.6)$ & 0.49 & 2.1 \\
\hline PTB7-Th:PNDI-F45T10 $(1: 1)^{\mathrm{b}}$ & 92 & 0.78 & $12.4(11.6)$ & 0.54 & 5.2 \\
\hline
\end{tabular}

a Conventional device structure: ITO/PEDOT:PSS (40 nm)/active layer/LiF $(1 \mathrm{~nm}) / \mathrm{Al}(100 \mathrm{~nm})$.

${ }^{\mathrm{b}}$ Inverted device structure: $\mathrm{ITO} / \mathrm{ZnO}(40 \mathrm{~nm}) /$ active layer $/ \mathrm{MoO}_{3}(10 \mathrm{~nm}) / \mathrm{Ag}(100 \mathrm{~nm})$.

c Solvent annealing.

${ }^{\mathrm{d}}$ Photocurrent density obtained by integrating the EQE with the AM1.5G spectrum are given in the parentheses.

e The average PCE from ten devices.

evaluate the spectral response of the all-PSCs and the accuracy of the photocurrent density from the $J-V$ measurements. As shown in Fig. 2b and Fig S5d, the all-PSCs exhibited EQE response in the wavelength region of $350-850 \mathrm{~nm}$, which were consistent with the absorption spectra of the corresponding blend films. Among these all-PSCs, the PTB7-Th:PNDI-FT10 solar cells with the D:A ratios of 2.5:1 and 1:1 presented relatively high EQEs with the maximum EQE over 70\% in the wavelength region of $600-700 \mathrm{~nm}$. It was noticed that the EQE profiles of the PTB7-Th:PNDI-FT10 all-PSCs varied with D:A ratios, which can be attributed to the different absorption contributions from the donor and acceptor polymers in the active layers. The photocurrent density, as calculated by integrating the EQE spectra with AM 1.5G solar spectrum, was in good agreement with the corresponding $J_{\text {sc }}$ from the $J-V$ measurements with mismatches less than $7 \%$ (Table 2), which confirmed the accuracy of the measured photovoltaic performance.

\subsection{Film morphology}

As the morphology of active layers is determinative for the photovoltaic performance, 2D grazing incidence wide angle X-ray scattering (GIWAXS) and atomic force microscopy (AFM) were employed to investigate the surface roughness, phase separation, polymer orientation and crystalline texture [61]. As shown in the 2D GIWAXS patterns and
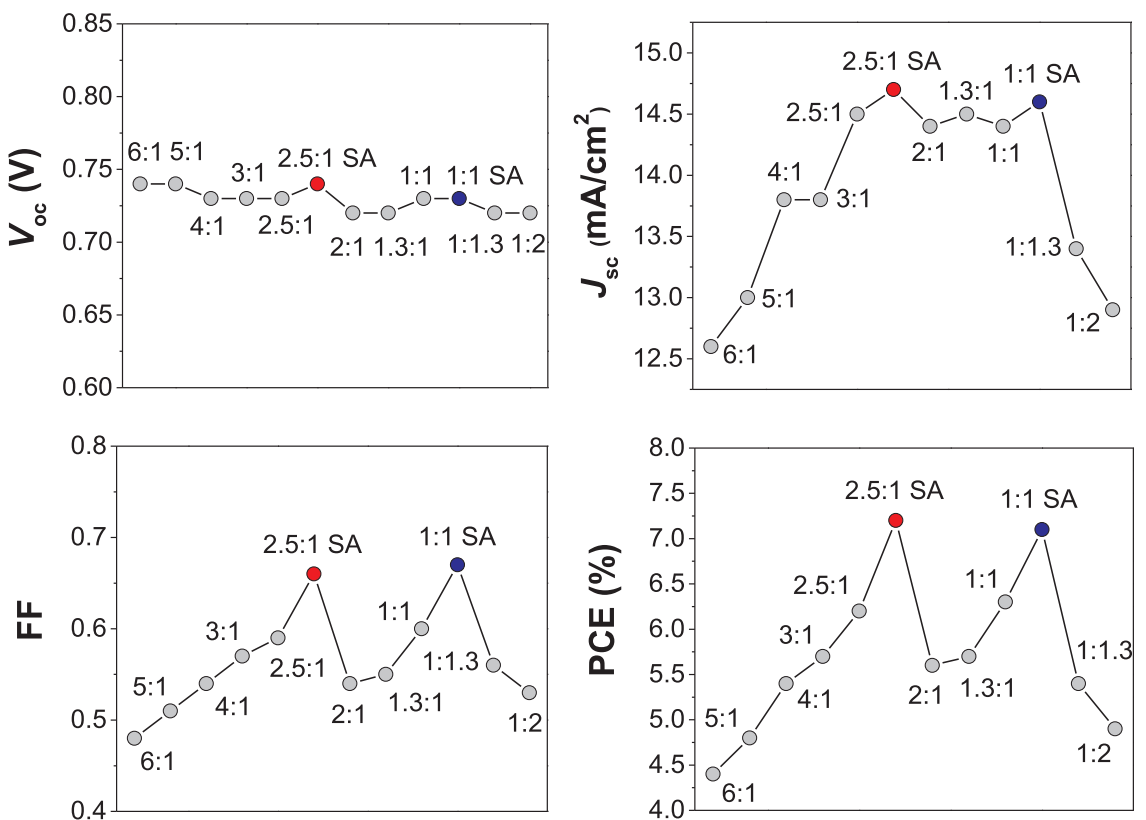

the corresponding line cuts of the neat polymer and blend films (Figs. $4 \mathrm{a}, \mathrm{S} 6$ and S7), the (100) diffraction peaks at $q_{x y} \approx$ 0.24-0.27 $\AA^{-1}$ due to the lamellar stacking were located at the in-plane (IP) direction, while the corresponding (010) diffraction peaks at $q_{z} \approx$ $1.60-1.70 \AA^{-1}$ due to the $\pi-\pi$ stacking were located at the out-of-plane (OOP) direction. This indicated that the two polymers in each blend tended to have strong preferential face-on orientation relative to the electrodes, which mostly retained the same orientation with the corresponding pristine polymers. To compare the $\pi-\pi$ stacking characteristics of the neat polymer and blend films in the charge transport direction (perpendicular to the electrodes), the $\pi-\pi$ coherence lengths (CL) were calculated using the full width at half maximum (FWHM) of the (010) diffraction peak via the Scherrer equation [62]. As summarized in Fig. $4 \mathrm{~b}$ and Table S3, increasing the content of thiophene units in the polymer backbones gradually reduced the CL of the neat polymer films, from $2.52 \mathrm{~nm}$ for F-N2200, to $1.35 \mathrm{~nm}$ for PNDI-FT50. This was a clear indication of decreased crystallinity of the polymers, which should stem from the gradually increased disorder of the polymer backbones. Moreover, the same trend for the CL changes was found in the different blend films with the D:A ratio of $1: 1$, where the CL values gradually declined from $1.85 \mathrm{~nm}$ for the PTB7-Th:F-N2200 blend, to $1.31 \mathrm{~nm}$ for the PTB7-Th:PNDI-FT50 blend, implying that increased disorder in acceptor polymers also suppressed the $\pi-\pi$ stacking of the polymers in
Fig. 3. Device parameters of the PTB7-Th:PNDI-FT10 all-PSCs as a function of D:A ratios. 

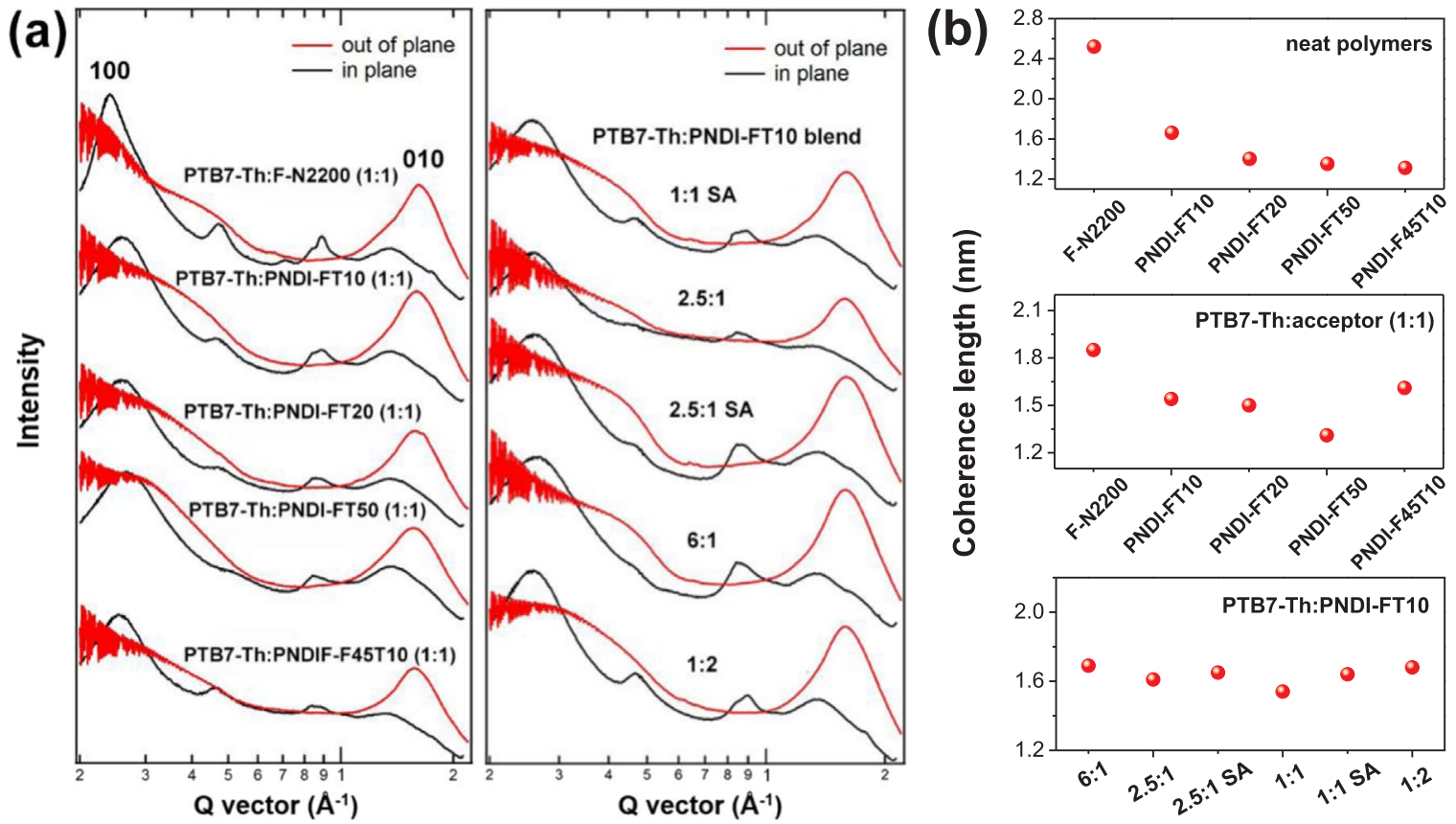

Fig. 4. (a) In-plane and out-of-plane line cuts of GIWAXS patterns of the blend films. (b) $\pi-\pi$ coherence lengths of the neat polymer and blend films.

the blends. In addition, increases in $\pi-\pi$ stacking distance were also found along with the increased disorder in the acceptor polymers (Table S4). As depicted in Fig S8, the AFM images from the PTB7-Th:F-N2200 and PTB7-Th:PNDI-FT10 blends with 1:1 ratio showed tiny fiber-like microstructures and small phase segregation with root-mean-square (RMS) roughness of $2.0 \mathrm{~nm}$ and $1.6 \mathrm{~nm}$, respectively. In contrast, the PTB7-Th:PNDI-FT20 and PTB7-Th:PNDI-FT50 blends presented larger aggregates and phase separation with higher RMS roughness of 2.2 and $4.1 \mathrm{~nm}$, respectively, implying larger phase separation. The smaller CL and larger phase separation in the PTB7-Th:PNDI-FT20 and PTB7Th:PNDI-FT50 blends were unfavorable for exciton dissociation and charge transport, which reduced the overall photovoltaic performance. The PTB7-Th:PNDI-F45T10 (1:1) blend showed a moderate CL of $1.61 \mathrm{~nm}$ and RMS roughness of $1.9 \mathrm{~nm}$, which may partially explain its medium performance.

In addition, as SA largely improved the performance of the PTB7Th:PNDI-FT10 all-PSCs, we also investigated how it affected the blend morphology. Similar to our previous report on the PTB7-Th:PNDI-T10 blend [23], SA can improve the $\pi-\pi$ stacking of the PTB7-Th:PNDIFT10 blends, as the (010) out-of-plane diffraction peaks were clearly enhanced after SA due to the extra time for polymer chain rearrangement. Upon SA, we noted that the CL of the PTB7-Th:F-N2200 $(1.85 \mathrm{~nm})$ and PTB7-Th:PNDI-FT10 $(1.64 \mathrm{~nm})$ blends were smaller than those of PTB7-Th:N2200 (1.96 nm) and PTB7-Th:PNDI-T10 $(2.05 \mathrm{~nm})$ blends [23], probably due to the less crystalline behavior of the two fluorinated acceptor polymers. This is in agreement with the DSC results above, where the fluorinated F-N2200 and PNDI-FT10 presented no detectable thermal transitions but the non-fluorinated N2200 and PNDI-T10 exhibited clear melting and crystallization transitions [23]. Moreover, Woo et al. demonstrated that fluorinated acceptor polymers usually tend to decrease the surface tension, which leads to well-intermixed blend morphology with smaller phase separation $[55,63]$.

At last, we investigated how the D:A ratios influence the morphology of the PTB7-Th:PNDI-FT10 blends. Interestingly, when the D:A ratios varied from $6: 1$ to $1: 2$ in the blend films, there was no significant change in the CL (1.50-1.70 nm), which indicated good miscibility of the two polymers. As shown in the AFM images, the PTB7-Th:PNDIFT10 blend films with D:A ratios of 2.5:1 and 1:1 presented very similar surface morphology with tiny fiber-like features and relatively low RMS roughness of 1.4 and $1.6 \mathrm{~nm}$, respectively. In contrast, the blends from the extreme D:A ratios of 6:1 and 1:2 exhibited larger and more segregated domains with higher RMS roughness of $3.2 \mathrm{~nm}$ and $3.6 \mathrm{~nm}$, respectively. The fine phase separation can increase the D:A interface area and facilitate the exciton dissociation. The different morphology disclosed by the GIWAXS and AFM measurements can partially explain the performance of the all-PSCs under the varied D:A ratios.

\subsection{Relative dielectric constants, binding energies and mobilities}

In order to further understand the origin of the photovoltaic performance described above, we measured the $\varepsilon_{\mathrm{r}}$ of the neat polymer and blend films by spectral impedance measurements. Using an equivalent circuit model, the average $\varepsilon_{\mathrm{r}}$ was determined by fitting over the frequency range of $1 \mathrm{kHz}-1 \mathrm{GHz}$. Figs. 5 and S9 depict the frequency-dependent $\varepsilon_{\mathrm{r}}$ in the pristine polymer and blend films. As summarized in Table 3 , the neat polymer and blend films of the fluorinated polymers $\mathrm{F}$ N2200 and PNDI-FT10 showed clearly higher $\varepsilon_{\mathrm{r}}$ as compared to the non-fluorinated polymers N2200 and PNDI-T10. As the content of the fluorinated units increased, the average $\varepsilon_{\mathrm{r}}$ of the blend films gradually increased from 3.28 for PTB7-Th:PNDI-F45T10 to 4.27 for PTB7-Th:FN2200. This can be attributed to the increased polarity of the fluorinated polymer backbones $[39,44,46]$. In PSCs, excitons should overcome the binding energy of CT state $\left(E_{B}^{C T}\right)$ to dissociate into free charges within the lifetime. Therefore, $E_{B}^{C T}$ is an influential factor for the charge generation and overall photocurrent [64]. $E_{B}^{C T}$ can be calculated by using Eq. (1) [37,39,65],

$E_{B}^{C T}=\frac{q^{2}}{4 \pi \varepsilon_{0} \varepsilon_{r} r}$

where $q$ is the elemental electron charge, $\varepsilon_{0}$ is the vacuum dielectric constant, $\varepsilon_{\mathrm{r}}$ is the relative dielectric constant of the blend film and $r$ is the radius of average diameter for electron-hole separation. Here, $r=$ $1.5 \mathrm{~nm}$ was used to calculate $\varepsilon_{\mathrm{r}}$, which is the commonly used value in organic solar cells $[44,65]$. Owing to the improved $\varepsilon_{\mathrm{r}}$, the blend films based on the fluorinated acceptors featured lower $E_{B}^{C T}$ compared to the blend films based on the non-fluorinated acceptors, which can facilitate the exciton dissociation (Table 3). This is probably one of the reasons for the increased $J_{\mathrm{sc}}$ in the all-PSCs based on the fluorinated acceptor polymers. 

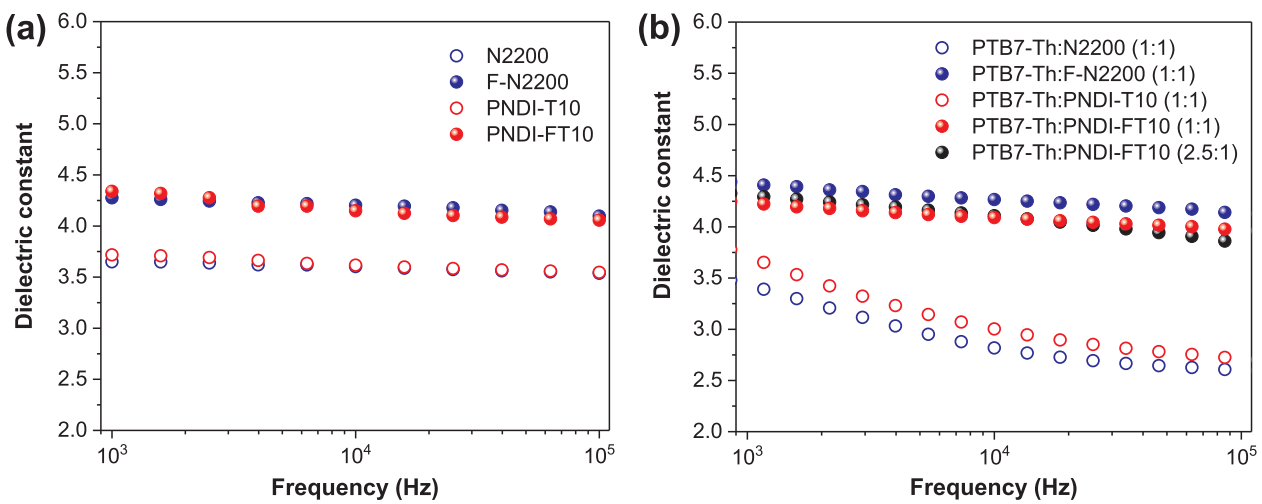

Fig. 5. (a) Relative dielectric constants versus frequency for the neat polymers. (b) Relative dielectric constants versus frequency for the blend films.
The hole and electron mobilities $\left(\mu_{\mathrm{h}}\right.$ and $\mu_{\mathrm{e}}$ ) of the blend films were measured by using the space charge limited current (SCLC) method, which can be calculated by using Eq. (2),

$J=\frac{9}{8} \varepsilon_{0} \varepsilon_{r} \mu \frac{V^{2}}{d^{3}}$

where $J$ is the current density, $\mu$ is the charge mobility at zero field, $\varepsilon_{0}$ is the free-space dielectric constant, $\varepsilon_{\mathrm{r}}$ is the relative dielectric constant of the polymer blend, $d$ is the thickness of the active layer, and $V$ is the effective voltage $V-V_{\mathrm{bi}}$. We note that a $\varepsilon_{\mathrm{r}}$ of 3 is usually used to calculate the mobilities of conjugated polymers in literature [66]. Since we measured the actual $\varepsilon_{\mathrm{r}}$ of each blend film in this work, the mobilities can be calculated in a more precise way by using the actual $\varepsilon_{\mathrm{r}}$. The $\mu_{\mathrm{h}}$ and $\mu_{\mathrm{e}}$ can be fitted from the slope of the $J^{1 / 2}-V$ curve. The $J-V$ curves and SCLC fits are summarized in Fig S10. As summarized in Table 3, the actual mobilities of the fluorinated polymer blends were slightly lower when the higher actual $\varepsilon_{\mathrm{r}}$ was used for calculation, instead of using the value of 3. All blend films showed relatively high $\mu_{\mathrm{h}}$ and $\mu_{\mathrm{e}}$ around the order of $10^{-4} \mathrm{~cm}^{2} \mathrm{~V}^{-1} \mathrm{~s}^{-1}$, and well balanced $\mu_{\mathrm{h}}$ and $\mu_{\mathrm{e}}$ with low $\mu_{\mathrm{h}} / \mu_{\mathrm{e}}$. This indicated that mobility was not a limiting factor for photovoltaic performance in this system. It also revealed that the small differences in mobilities should not account for the clear improvement in the $J_{\mathrm{sc}}$ of the all-PSCs based on the fluorinated acceptor polymers.

\subsection{PL quenching characterization}

In order to study the efficiencies of exciton dissociation, photoluminescence (PL) quenching of the blend films were measured. As depicted in Fig. 6, the PL peaks of the neat polymer PTB7-Th and the acceptor polymers were around $766 \mathrm{~nm}$ and $835 \mathrm{~nm}$, respectively. The steady-state PL quenching efficiency $(\triangle \mathrm{PL})$ can be inferred by using Eq. (3) $[23,67]$,

$\Delta \mathrm{PL}=1-\frac{\mathrm{PL}_{\text {blend }}}{\mathrm{PL}_{\text {polymer }}}$ where $\mathrm{PL}_{\mathrm{blend}}$ and $\mathrm{PL}_{\text {polymer }}$ are the integral PL counts of the blends and neat polymer films, respectively.

All polymer:polymer blends showed very high $\Delta \mathrm{PL}$ relative to the donor polymer $\left(\Delta \mathrm{PL}_{\mathrm{D}}\right)$ with the value over $95 \%$, indicating that the excitons generated in PTB7-Th can be efficiently dissociated. On the other hand, the $\Delta \mathrm{PL}$ relative to the acceptor polymers $\left(\Delta \mathrm{PL}_{\mathrm{A}}\right)$ were slightly lower and the emission from the acceptor polymers at $835 \mathrm{~nm}$ were still observed in the blend films. The fluorinated blends PTB7Th:F-N2200 and PTB7-Th:PNDI-FT10 presented higher $\triangle \mathrm{PL}_{\mathrm{A}}$ of $87 \%$ and $95 \%$, respectively, as compared to the two non-fluorinated blends PTB7-Th:N2200 and PTB7-Th:PNDI-T10 with moderate $\Delta \mathrm{PL}_{\mathrm{A}}$ of $65 \%$ and $80 \%$, respectively [23]. As the PL from the donors was almost quenched in all the four blends, we infer that there were no large phase separation or big pure polymer domains in any of the blend films. Associated with the GIWAXS and AFM measurements, the blend films based on the fluorinated and non-fluorinated acceptor polymers presented very similar phase separation, domain sizes and crystal textures [23]. On this basis, the enhanced PL quenching efficiencies in the fluorinated blends can be explained by the reduced binding energy due to the higher $\varepsilon_{\mathrm{r}}$.

\subsection{Recombination characterization}

In order to study the correlation between $\varepsilon_{\mathrm{r}}$ and recombination losses in this system, first, we quantified the bimolecular recombination by measuring the EQE profiles with and without the illumination of bias light (Fig S11 and Fig S12). Recent reports have proved that this is a more precise method as compared to measuring $J_{\mathrm{sc}}$ as a function of light intensity $[68,69]$. Because bimolecular recombination is strongly correlated with charge carrier density, a bias light can increase charge carrier density in a film and thus stimulate bimolecular recombination at short-circuit condition [70]. In this case, the EQE obtained under the bias light should decline as compared to the EQE without the bias light. The average bimolecular recombination efficiency $\left(\eta_{\mathrm{BR}}\right)$ over the whole

Table 3

Relative dielectric constants, binding energies and SCLC mobilities of the blend films.

\begin{tabular}{|c|c|c|c|c|c|}
\hline Donor:acceptor & $\varepsilon_{\mathrm{r}}^{\mathrm{a}}$ & $E_{B}^{C T \mathrm{~b}}(\mathrm{eV})$ & $\operatorname{SCLC} \mu_{\mathrm{h}}{ }^{\mathrm{c}}\left(\mathrm{cm}^{2} \mathrm{~V}^{-1} \mathrm{~s}^{-1}\right)$ & $\operatorname{SCLC} \mu_{\mathrm{e}}^{\mathrm{c}}\left(\mathrm{cm}^{2} \mathrm{~V}^{-1} \mathrm{~s}^{-1}\right)$ & $\mu_{\mathrm{h}} / \mu_{\mathrm{e}}$ \\
\hline PTB7-Th:N2200 (1:1) & 3.05 & 0.32 & $2.0 \times 10^{-3}\left(2.0 \times 10^{-3}\right)^{\mathrm{d}}$ & $2.0 \times 10^{-4}\left(2.0 \times 10^{-4}\right)^{\mathrm{d}}$ & 10.0 \\
\hline PTB7-Th:PNDI-T10 (1:1) & 2.88 & 0.34 & $8.9 \times 10^{-4}\left(8.5 \times 10^{-4}\right)$ & $4.5 \times 10^{-4}\left(4.3 \times 10^{-4}\right)$ & 2.0 \\
\hline PTB7-Th:F-N2200 (1:1) & 4.27 & 0.23 & $3.5 \times 10^{-4}\left(5.0 \times 10^{-4}\right)$ & $1.2 \times 10^{-4}\left(1.7 \times 10^{-4}\right)$ & 2.9 \\
\hline PTB7-Th:PNDI-FT10 (1:1) & 4.10 & 0.24 & $4.8 \times 10^{-4}\left(6.5 \times 10^{-4}\right)$ & $1.6 \times 10^{-4}\left(2.2 \times 10^{-4}\right)$ & 3.0 \\
\hline PTB7-Th:PNDI-FT10 (2.5:1) & 4.10 & 0.24 & $6.7 \times 10^{-4}\left(9.1 \times 10^{-4}\right)$ & $3.4 \times 10^{-4}\left(4.6 \times 10^{-4}\right)$ & 2.0 \\
\hline PTB7-Th:PNDI-FT20 (1:1) & 3.89 & 0.25 & $2.2 \times 10^{-4}\left(2.8 \times 10^{-4}\right)$ & $1.4 \times 10^{-4}\left(1.8 \times 10^{-4}\right)$ & 1.6 \\
\hline PTB7-Th:PNDI-FT50 (1:1) & 3.44 & 0.28 & $9.6 \times 10^{-5}\left(1.1 \times 10^{-4}\right)$ & $8.7 \times 10^{-5}\left(1.0 \times 10^{-4}\right)$ & 1.1 \\
\hline PTB7-Th:PNDI-F45T10 (1:1) & 3.28 & 0.30 & $2.7 \times 10^{-4}\left(2.9 \times 10^{-4}\right)$ & $2.2 \times 10^{-4}\left(2.4 \times 10^{-4}\right)$ & 1.2 \\
\hline
\end{tabular}

${ }^{\text {a }}$ Average $\varepsilon_{\mathrm{r}}$ of the blend film with fitting error of \pm 0.01 .

${ }^{\mathrm{b}}$ Calculated for $r=1.5 \mathrm{~nm}$.

c SCLC mobilities calculated from the measured $\varepsilon_{\mathrm{r}}$.

${ }^{\mathrm{d}}$ SCLC mobilities calculated from the $\varepsilon_{\mathrm{r}}$ of 3 . 

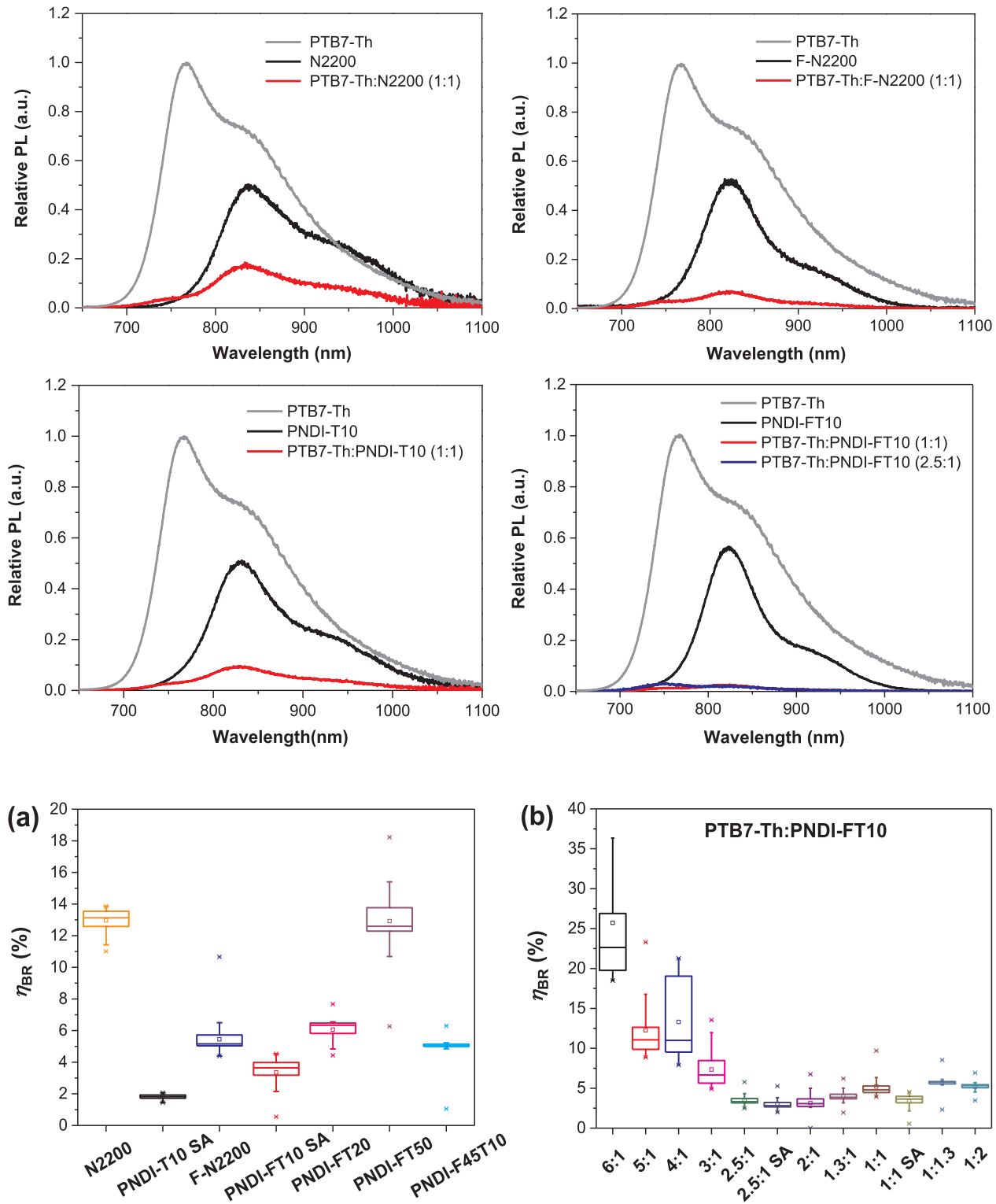

Fig. 6. The proportional PL counts of the neat polymer and blend films.
EQE wavelength can quantitatively reflect the bimolecular recombination, which is denoted by $\eta_{\mathrm{BR}}=\mathrm{EQE}_{\text {nobias }} / \mathrm{EQE}_{\text {bias }}-1[68,69]$. Fig. 7a illustrates the average $\eta_{\mathrm{BR}}$ of the all-PSCs based on different acceptor polymers. Except for the high $\eta_{\mathrm{BR}}$ of around 13\% from the N2200 and PNDI-FT50-based all-PSCs, the all-PSCs based on F-N2200, PNDI-FT10, PNDI-FT20 and PNDI-F45T10 gave similarly lower average $\eta_{\mathrm{BR}}$ of $3-6 \%$, which indicated that bimolecular recombination did not account for the main losses of $J_{\text {sc }}$ in the latter four all-PSCs. For the PTB7-Th:PNDI-FT10 all-PSCs with different D:A ratios, low average $\eta_{\mathrm{BR}}$ within $5 \%$ were observed when the D:A ratios varied in a large range from 2.5:1 to 1:2 (Fig. 7b). This revealed that the separated free charges were efficiently transported and collected by the electrodes, which was also consistent with the relatively high and well balanced mobilities in the blend films.

In addition, we estimated geminate and total recombination losses from the $J_{\text {sc }}$, saturated photocurrent density $\left(J_{\text {sat }}\right)$ and theoretical maximum photocurrent density $\left(J_{\max }\right)$ of the PTB7-Th:PNDI-T10 and PTB7-Th:PNDI-FT10 all-PSCs. The geminate recombination loss $\left(\eta_{\mathrm{G}}\right)$ was calculated by using the equation $\eta_{\mathrm{G}}=1-\left(J_{\mathrm{sat}} / J_{\text {max }}\right)$, and the total recombination loss $\left(\eta_{\mathrm{T}}\right)$ was calculated by using the equation $\eta_{\mathrm{T}}=1-$ $\left(J_{\mathrm{sc}} / J_{\max }\right)$. Since the best device performance was obtained from the conventional PTB7-Th:PNDI-T10 all-PSCs $(6.9 \%)$ and the inverted
PTB7-Th:PNDI-FT10 all-PSCs (7.3\%), we should point out that the corresponding photocurrent density was recorded from the best performing all-PSCs. The $J_{\text {sat }}$ of the all-PSCs was recorded by applying reverse bias voltage up to $-3 \mathrm{~V}$ during the $J-V$ measurements. As shown in Fig S13a, fast saturation of the photocurrent was observed along the bias voltage for each all-PSC, indicating that the intrinsic driving force was high enough to extract most of the free charges to the electrodes, and the non-geminate recombination (e.g. bimolecular recombination and trap-assisted recombination) was not significant in the two all-PSCs. Compared to the PTB7-Th:PNDI-T10 all-PSC, the PTB7Th:PNDI-FT10 all-PSC exhibited slightly slower saturation of the photocurrent under reverse bias voltage, which suggested that larger nongeminate recombination loss existed in this solar cell. If we assume that all photons absorbed by the active layer can be converted to photocurrent (internal quantum yield is $100 \%$ ), the $J_{\max }$ of the all-PSCs can be calculated by transfer matrix formalism (TMF) via integrating the simulated absorption spectrum of the active layer with an AM 1.5G spectrum [71]. Under the optimized active layer thickness of $95 \mathrm{~nm}$, the simulated $J_{\max }$ were $18.6 \mathrm{~mA} / \mathrm{cm}^{2}$ and $18.7 \mathrm{~mA} / \mathrm{cm}^{2}$ for the conventional and inverted PTB7-Th:PNDI-FT10 all-PSCs, respectively. Lower $J_{\max }$ of $16.8 \mathrm{~mA} / \mathrm{cm}^{2}$ and $16.6 \mathrm{~mA} / \mathrm{cm}^{2}$ were obtained from the conventional and inverted PTB7-Th:PNDI-T10 all-PSCs, respectively, which 
Table 4

Summary of $J_{\mathrm{sc}}, J_{\mathrm{sat}}$ and $J_{\mathrm{max}}$ and the related recombination losses.

\begin{tabular}{lllllll}
\hline All-PSC & $\begin{array}{l}J_{\mathrm{sc}}[\mathrm{mA} / \\
\left.\mathrm{cm}^{2}\right]\end{array}$ & $\begin{array}{l}J_{\mathrm{sat}}[\mathrm{mA} / \\
\left.\mathrm{cm}^{2}\right]\end{array}$ & $\begin{array}{l}J_{\mathrm{max}}[\mathrm{mA} / \\
\left.\mathrm{cm}^{2}\right]\end{array}$ & $\eta_{\mathrm{G}}{ }^{c}$ & $\eta_{\mathrm{BR}}$ & $\eta_{\mathrm{T}}{ }^{d}$ \\
\hline $\begin{array}{c}\text { PTB7-Th:PNDI-T10 } \\
\text { SA }\end{array}$ & 12.9 & 13.6 & 16.8 & $19.0 \%$ & $1.8 \%$ & $23.2 \%$ \\
$\begin{array}{c}\text { PTB7-Th:PNDI- } \\
\text { FT10 SA }\end{array}$ & 14.6 & 16.2 & 18.7 & $13.4 \%$ & $3.3 \%$ & $21.9 \%$ \\
\hline
\end{tabular}

${ }^{\text {a }}$ Conventional device structure: ITO/PEDOT:PSS (40 nm)/active layer/LiF (1 nm)/Al $(100 \mathrm{~nm})$.

${ }^{\mathrm{b}}$ Inverted device structure: ITO/ZnO $(40 \mathrm{~nm}) /$ active layer $/ \mathrm{MoO}_{3} \quad(10 \mathrm{~nm}) / \mathrm{Ag}$ $(100 \mathrm{~nm})$.

${ }^{\mathrm{c}} \eta_{\mathrm{G}}=1-\left(J_{\mathrm{sat}} / J_{\mathrm{max}}\right){ }^{d} \eta_{\mathrm{T}}=1-\left(J_{\mathrm{sc}} / J_{\mathrm{max}}\right)$.

were recorded under the optimized active layer thickness of $90 \mathrm{~nm}$. One of the reasons that led to the higher simulated $J_{\max }$ of the PTB7Th:PNDI-FT10 all-PSC, as compared to the PTB7-Th:PNDI-T10 all-PSC, may stem from its more efficient exciton dissociation and photon absorption, where the former was supported by the PL quenching measurements, and the latter was supported by the higher simulated absorptance of the photons in the PTB7-Th:PNDI-FT10 active layers in both the conventional and inverted devices, as compared to the PTB7Th:PNDI-T10 active layers (Fig S13b).

Table 4 summarizes the $\eta_{\mathrm{G}}, \eta_{\mathrm{BR}}$ and $\eta_{\mathrm{T}}$ values for the PTB7-Th:PNDIFT10 and PTB7-Th:PNDI-T10 all-PSCs. Under the best operating condition of the devices, the all-PSCs with the fluorinated acceptor can reduce the geminate recombination $\left(\eta_{\mathrm{G}} \approx 13.4 \%\right.$ for PTB7-Th:PNDIFT10 and $\eta_{\mathrm{G}} \approx 19.0 \%$ for PTB7-Th:PNDI-T10). This was mainly due to the higher $\varepsilon_{\mathrm{r}}$ and lower binding energy, leading to more efficient exciton dissociation and charge generation in the PTB7-Th:PNDI-FT10 blend. Although a higher $\eta_{\mathrm{BR}}$ indicated more agitated bimolecular recombination in the PTB7-Th:PNDI-FT10 all-PSC as compared to the PTB7-Th:PNDI-T10 all-PSC, the former still held a lower $\eta_{\mathrm{T}}$. In brief, the improved $J_{\text {sc }}$ of the PTB7-Th:PNDI-FT10 all-PSC can be attributed to the synergistic effects of more photon harvesting and more efficient exciton dissociation in the active layer.

\section{Conclusion}

In summary, we synthesized a series of fluorinated NDI-based acceptor polymers with the intention to modulate the crystallinity and $\varepsilon_{\mathrm{r}}$ of the polymer:polymer blends. Increasing the content of thiophene units gradually reduced the crystallinity and largely improved the molecular weights of these random copolymers. The fluorinated acceptor polymers presented enhanced $\varepsilon_{\mathrm{r}}$, which tended to improve the charge generation and suppress the geminate recombination in the blends. Among the five fluorinated polymers, PNDI-FT10 featured desired miscibility with the donor PTB7-Th, more photon harvesting, improved exciton dissociation and less recombination losses, which synergistically led to the high PCE of $7.3 \%$. The $J_{\mathrm{sc}}$ of $14.7 \mathrm{~mA} / \mathrm{cm}^{2}$ is among the highest values in all-PSCs, surpassing the $J_{\mathrm{sc}}$ of $12.9 \mathrm{~mA} / \mathrm{cm}^{2}$ recorded for the PTB7-Th:PNDI-T10 all-PSC. Provided that there are enough energy offsets and optimal morphology, further enhancing $\varepsilon_{\mathrm{r}}$ of acceptor polymers can be a facile approach to boost $J_{\mathrm{sc}}$ and thus the PCEs of all-PSCs. This work opens a new avenue for molecular design of acceptor polymers for high-performance all-PSCs. We also have, for the first time, achieved high PCEs over $6 \%$ for a large variation of D:A ratios in the all-PSCs, which demonstrates good morphological tolerance and robust production capability of the all-PSCs.

\section{Experimental section}

\subsection{Material characterization}

GPC was carried out on an Agilent PL-GPC 220 Integrated High
Temperature GPC/SEC System with refractive index and viscometer detectors using $3 \times$ PLgel $10 \mu \mathrm{m}$ MIXED-B LS, $300 \times 7.5 \mathrm{~mm}$ columns. The eluent was $1,2,4$-trichlorobenzene at $150{ }^{\circ} \mathrm{C}$. The molecular weights were calculated according to relative calibration with polystyrene standards. Thermogravimetric analysis (TGA) was carried out on a METTLER TOLEDO thermogravimetric analyzer TGA/DSC $3+$, from $50{ }^{\circ} \mathrm{C}$ to $550{ }^{\circ} \mathrm{C}$ at a heating rate of $10{ }^{\circ} \mathrm{C} / \mathrm{min}$ under $\mathrm{N}_{2}$ flow. Differential scanning calorimetry (DSC) was carried out on a METTLER TOLEDO differential scanning calorimeter DSC 2 , from $0{ }^{\circ} \mathrm{C}$ to $320{ }^{\circ} \mathrm{C}$ at a heating and cooling rate of $10{ }^{\circ} \mathrm{C} / \mathrm{min}$ under $\mathrm{N}_{2}$ flow. UV-Vis-NIR absorption spectra were measured with a PerkinElmer Lambda 900 UV-Vis-NIR absorption spectrometer. PL spectra were recorded by using an Andor spectrometer Shamrock SR-303i, coupled to a Newton EMCCD detector. Square wave voltammetry (SWV) measurements were carried out on a CH-Instruments 650A Electrochemical Workstation. A three-electrode setup was used with platinum wires for both the working electrode and counter electrode, and $\mathrm{Ag} / \mathrm{Ag}^{+}$was used for the reference electrode calibrated with a ferrocene/ferrocenyl couple ( $\mathrm{Fc}$ / $\mathrm{Fc}^{+}$). A $0.1 \mathrm{M}$ nitrogen-saturated solution of tetrabutylammonium hexafluorophosphate $\left(\mathrm{Bu}_{4} \mathrm{NPF}_{6}\right)$ in anhydrous acetonitrile was used as the supporting electrolyte. The polymer films were deposited onto the working electrode from the $o$ DCB solution.

\subsection{All-PSC fabrication and characterization}

Inverted all-PSCs were fabricated using an indium tin oxide (ITO)/ $\mathrm{ZnO}(40 \mathrm{~nm}) /$ active layer $/ \mathrm{MoO}_{3}(10 \mathrm{~nm}) / \mathrm{Ag}(100 \mathrm{~nm})$ structure. Solgel $\mathrm{ZnO}$ was prepared by mixing zinc acetate dihydrate $(0.5 \mathrm{M})$, ethanolamine $(0.5 \mathrm{M})$ in 2-methoxy ethanol for $1 \mathrm{~h}$ at room temperature. Sol-gel $\mathrm{ZnO}$ (thickness of around $40 \mathrm{~nm}$, determined by a Dektak $6 \mathrm{M}$ surface profilometer) was spin-coated onto the ITO-coated glass substrate at a spinning rate of $4000 \mathrm{rpm}$ for $60 \mathrm{~s}$, followed by annealing at $150{ }^{\circ} \mathrm{C}$ for $5 \mathrm{~min}$. The different weight ratios of the donor and acceptor polymers were dissolved in $o D C B$ at $70{ }^{\circ} \mathrm{C}$ overnight (the optimized ratio was 1:1). The active layer was then spin-coated from warm $o D C B$ solution on top of the $\mathrm{ZnO}$ layer in a glove box. The total concentration of the solution was $15 \mathrm{mg} \mathrm{mL}^{-1}$. After spin-coating, the active layers were solvent annealed under $o \mathrm{DCB}$ atmosphere for $1.5 \mathrm{~h}$. After that, the films were directly transferred to a vapor deposition system inside of a glove box. $\mathrm{MoO}_{3}(10 \mathrm{~nm})$ and $\mathrm{Ag}(100 \mathrm{~nm})$ were deposited via a mask under $3 \times 10^{-4} \mathrm{~Pa}$ vacuum onto the active layer. The active areas of the device are $9 \mathrm{~mm}^{2}$ and $16 \mathrm{~mm}^{2}$, which was defined by the overlap of the ITO and Al electrode and was measured carefully using a microscope.

All devices were fabricated and tested in a glove box with temperature: $\sim 20^{\circ} \mathrm{C}$, oxygen: $\sim 0.2 \mathrm{ppm}$ and water: $\sim 0.1 \mathrm{ppm}$. The $J-V$ curves were recorded in backward scan direction and the efficiency was calculated from the $J-V$ characteristics recorded by a Keithley 2400 source meter under illumination from a tungsten-halogen lamp filtered by a Hoya LB120 daylight filter at an intensity of $100 \mathrm{~mW} \mathrm{~cm}{ }^{-2}$, which was checked with a calibrated Si photodiode.

EQE measurements were performed in a home-built setup. All devices were kept in a nitrogen-filled box with a quartz window and illuminated through a circular aperture with $2 \mathrm{~mm}$ diameter. The white light of a $50 \mathrm{~W}$ tungsten halogen lamp (Osram 64610) was modulated with a mechanical chopper (Stanford Research, SR 540) and passed through a monochromator (Oriel, Cornerstone 130). For the EQE under bias light, a $530 \mathrm{~nm}$ high power LED (Thorlabs) was used to illuminate the solar cell simultaneously under the mechanically modulated monochromatic light and the unmodulated LED light. For both unbiased and bias EQE measurements, the differential photocurrent density was picked up by a lock-in amplifier. The current was recorded as the voltage over a $50 \Omega$ resistance and was converted to EQE profile by comparing the data with a calibrated silicon reference cell. 


\subsection{Capacitor fabrication and characterization}

The device structure was the same as the inverted solar cell by using an indium tin oxide (ITO)/ZnO $(40 \mathrm{~nm}) /$ active layer $(90 \mathrm{~nm}) / \mathrm{MoO}_{3}$ $(10 \mathrm{~nm}) / \mathrm{Ag}(100 \mathrm{~nm})$ structure. Sol-gel $\mathrm{ZnO}$ (thickness of around $40 \mathrm{~nm}$, determined by a Dektak $6 \mathrm{M}$ surface profilometer) was spincoated onto the ITO-coated glass substrate at a spinning rate of $4000 \mathrm{rpm}$ for $60 \mathrm{~s}$, followed by annealing at $150{ }^{\circ} \mathrm{C}$ for $5 \mathrm{~min}$. The polymers were dissolved in $o \mathrm{DCB}$ at $70{ }^{\circ} \mathrm{C}$ overnight. The active layer was then spin-coated from the warm $o \mathrm{DCB}$ solution on top of the $\mathrm{ZnO}$ layer in a glove box. After spin-coating, the films were directly transferred to a vapor deposition system inside of a glove box. $\mathrm{MoO}_{3}(10 \mathrm{~nm})$ and $\mathrm{Ag}(100 \mathrm{~nm})$ were deposited via a mask under $3 \times 10^{-4} \mathrm{~Pa}$ vacuum onto the active layer. The active area of the device is $16 \mathrm{~mm}^{2}$, which was defined by the overlap of the ITO and Al electrode and was measured carefully using a microscope.

Impedance measurements were performed by using an electrochemical station (Solartron SI1260 impedance/gain-phase analyzer) and a data acquisition software (SMaRT v3.3.1) with a DC level of $0 \mathrm{~V}$ and AC perturbation voltage of $20 \mathrm{mV}$. All the measurements were performed in $\mathrm{N}_{2}$ atmosphere at room temperature. Impedance spectra were analyzed by ZView modeling software (Scribner). The geometric capacitance $\left(C_{g}\right)$ was determined by fitting impedance response of the device to the equivalent circuit $\mathrm{R}(\mathrm{RC})$, in the $1 \mathrm{kHz}$ to $1 \mathrm{GHz}$ frequency range. $\varepsilon_{\mathrm{r}}$ was calculated by using Eq. (4) [41].

$C_{g}=\varepsilon_{0} \varepsilon_{r} \frac{A}{d}$

where $\varepsilon_{0}$ is the free-space dielectric constant, $A$ is the active area of the device and $d$ is the thickness of the active layer.

\subsection{Grazing incidence wide-angle X-ray scattering (GIWAXS) measurements}

Grazing incidence X-ray scattering characterization of the thin films was performed on beam 7.3.3. at the Advanced Light Source [72]. Samples were prepared on $\mathrm{Si}$ substrates by using the same procedure as that used for all-PSCs. A $10 \mathrm{keV}$ X-ray beam was incident at a grazing angle of $0.12-0.16^{\circ}$, selected to maximize the scattering intensity from the samples. The scattered x-rays were detected using a Dectris Pilatus $2 \mathrm{M}$ photon counting detector.

\section{Acknowledgements}

We thank the EU projects OSNIRO (FP7-PEOPLE-2013-ITN, Grant agreement no.: 607585) and SUNFLOWER (FP7-ICT-2011-7, Grant number: 287594), the Swedish Research Council, the Swedish Research Council Formas, the Swedish Energy Agency and Chalmers Area of Advance Energy and the COST ActionStableNextSol. MP1307 for financial support. R.A.J.J acknowledges funding from the European Research Council under the European Union's Seventh Framework Programme (FP/2007-2013)/ERC Grant Agreement No. 339031 and the Ministry of Education, Culture, and Science (NWO Gravity program 024.001.035). B.L and W.M acknowledge the support from Ministry of Science and Technology (No. 2016YFA0200700), NSFC (21504066, 21534003). X-ray data was acquired at beamlines 7.3.3 at the Advanced Light Source, which is supported by the Director, Office of Science, Office of Basic Energy Sciences, of the U.S. Department of Energy under Contract No. DE-AC02-05CH11231. The authors thank Chenhui Zhu at beamline 7.3.3 for assistance with data acquisition. The research leading to these results has received funding from the People Programme (Marie Curie Actions) of the European Union's Seventh Framework Programme (FP7/2007-2013) under REA grant agreement no. 608743 . This publication reflects only the view of the authors and the European Union is not liable for any use that may be made of the information contained herein.

\section{Competing financial interests}

The authors declare no competing financial interest.

\section{Appendix A. Supporting information}

Supplementary data associated with this article can be found in the online version at http://dx.doi.org/10.1016/j.nanoen.2018.01.012.

\section{References}

[1] A.J. Heeger, Adv. Mater. 26 (2014) 10.

[2] S.B. Darling, F. You, RSC Adv. 3 (2013) 17633.

[3] J. Zhao, Y. Li, G. Yang, K. Jiang, H. Lin, H. Ade, W. Ma, H. Yan, Nat. Energy 1 (2016) 15027.

[4] W. Zhao, D. Qian, S. Zhang, S. Li, O. Inganäs, F. Gao, J. Hou, Adv. Mater. 28 (2016) 4734.

[5] W. Zhao, S. Li, H. Yao, S. Zhang, Y. Zhang, B. Yang, J. Hou, J. Am. Chem. Soc. 139 (2017) 7148.

[6] D. Baran, R.S. Ashraf, D.A. Hanifi, M. Abdelsamie, N. Gasparini, J.A. Rohr, S. Holliday, A. Wadsworth, S. Lockett, M. Neophytou, C.J.M. Emmott, J. Nelson, C.J. Brabec, A. Amassian, A. Salleo, T. Kirchartz, J.R. Durrant, I. McCulloch, Nat. Mater. 16 (2017) 363

[7] A. Anctil, C.W. Babbitt, R.P. Raffaelle, B.J. Landi, Environ. Sci. Technol. 45 (2011) 2353.

[8] M. Jørgensen, K. Norrman, S.A. Gevorgyan, T. Tromholt, B. Andreasen, F.C. Krebs, Adv. Mater. 24 (2012) 580.

[9] Y.-Y. Lai, Y.-J. Cheng, C.-S. Hsu, Energy Environ. Sci. 7 (2014) 1866.

[10] A. Facchetti, Mater. Today 16 (2013) 123.

[11] H. Kang, W. Lee, J. Oh, T. Kim, C. Lee, B.J. Kim, Acc. Chem. Res. 49 (2016) 2424.

[12] H. Benten, D. Mori, H. Ohkita, S. Ito, J. Mater. Chem. A 4 (2016) 5340.

[13] X. Xu, Z. Li, W. Zhang, X. Meng, X. Zou, D. Di Carlo Rasi, W. Ma, A. Yartsev, M.R. Andersson, R.A.J. Janssen, E. Wang, Adv. Energy Mater. 7 (2017) 1700908.

[14] Z. Li, W. Zhang, X. Xu, Z. Genene, D. Di Carlo Rasi, W. Mammo, A. Yartsev, M.R. Andersson, R.A.J. Janssen, E. Wang, Adv. Energy Mater. 7 (2017) 1602722.

[15] S.E. Root, S. Savagatrup, A.D. Printz, D. Rodriquez, D.J. Lipomi, Chem. Rev. 117 (2017) 6467.

[16] J.W. Jung, J.W. Jo, C.-C. Chueh, F. Liu, W.H. Jo, T.P. Russell, A.K.Y. Jen, Adv. Mater. 27 (2015) 3310.

[17] Y.-J. Hwang, B.A.E. Courtright, A.S. Ferreira, S.H. Tolbert, S.A. Jenekhe, Adv. Mater. 27 (2015) 4578.

[18] T. Kim, J.-H. Kim, T.E. Kang, C. Lee, H. Kang, M. Shin, C. Wang, B. Ma, U. Jeong, T, S. Kim, B.J. Kim, Nat. Commun. 6 (2015) 8547.

[19] S. Li, H. Zhang, W. Zhao, L. Ye, H. Yao, B. Yang, S. Zhang, J. Hou, Adv. Energy Mater. 6 (2016) 1501991.

[20] S. Liu, Z. Kan, S. Thomas, F. Cruciani, J.-L. Brédas, P.M. Beaujuge, Angew. Chem. Int. Ed. 55 (2016) 12996.

[21] Y. Guo, Y. Li, O. Awartani, J. Zhao, H. Han, H. Ade, D. Zhao, H. Yan, Adv. Mater. 28 (2016) 8483.

[22] X. Long, Z. Ding, C. Dou, J. Zhang, J. Liu, L. Wang, Adv, Mater. 28 (2016) 6504.

[23] Z. Li, X. Xu, W. Zhang, X. Meng, W. Ma, A. Yartsev, O. Inganäs, M.R. Andersson, R.A.J. Janssen, E. Wang, J. Am. Chem. Soc. 138 (2016) 10935.

[24] Z. Li, X. Xu, W. Zhang, Z. Genene, W. Mammo, A. Yartsev, M.R. Andersson, R.A.J. Janssen, E. Wang, J. Mater. Chem. A 5 (2017) 11693.

[25] S. Liu, X. Song, S. Thomas, Z. Kan, F. Cruciani, F. Laquai, J.-L. Bredas, P.M. Beaujuge, Adv. Energy Mater. 7 (2017) 1602574.

[26] J. Jung, W. Lee, C. Lee, H. Ahn, B.J. Kim, Adv. Energy Mater. 6 (2016) 1600504.

[27] L. Gao, Z.-G. Zhang, L. Xue, J. Min, J. Zhang, Z. Wei, Y. Li, Adv. Mater. 28 (2016) 1884.

[28] J. Oh, K. Kranthiraja, C. Lee, K. Gunasekar, S. Kim, B. Ma, B.J. Kim, S.-H. Jin, Adv. Mater. 28 (2016) 10016.

[29] B. Fan, L. Ying, Z. Wang, B. He, X. Jiang, F. Huang, Y. Cao, Energy Environ. Sci. 10 (2017) 1243.

[30] Y. Guo, Y. Li, O. Awartani, H. Han, J. Zhao, H. Ade, H. Yan, D. Zhao, Adv. Mater. 29 (2017) 1700309.

[31] Z. Li, X. Xu, W. Zhang, X. Meng, Z. Genene, W. Ma, W. Mammo, A. Yartsev, M.R. Andersson, R.A.J. Janssen, E. Wang, Energy Environ. Sci. 10 (2017) 2212.

[32] Z.-G. Zhang, Y. Yang, J. Yao, L. Xue, S. Chen, X. Li, W. Morrison, C. Yang, Y. Li, Angew. Chem. Int. Ed. 56 (2017) 13503.

[33] B. Fan, L. Ying, P. Zhu, F. Pan, F. Liu, J. Chen, F. Huang, Y. Cao, Adv. Mater. 29 (2017) 1703906

[34] S. Xiao, Q. Zhang, W. You, Adv. Mater. 29 (2016) 1601391.

[35] Z. He, B. Xiao, F. Liu, H. Wu, Y. Yang, S. Xiao, C. Wang, T.P. Russell, Y. Cao, Nat. Photonics 9 (2015) 174.

[36] V. Vohra, K. Kawashima, T. Kakara, T. Koganezawa, I. Osaka, K. Takimiya, H. Murata, Nat. Photonics 9 (2015) 403.

[37] L.J.A. Koster, S.E. Shaheen, J.C. Hummelen, Adv. Energy Mater. 2 (2012) 1246.

[38] I. Constantinou, X. Yi, N.T. Shewmon, E.D. Klump, C. Peng, S. Garakyaraghi, C.K. Lo, J.R. Reynolds, F.N. Castellano, F. So, Adv. Energy Mater. 7 (2017) 1601947.

[39] P. Yang, M. Yuan, D.F. Zeigler, S.E. Watkins, J.A. Lee, C.K. Luscombe, J. Mater. Chem. C 2 (2014) 3278. 
[40] N. Cho, C.W. Schlenker, K.M. Knesting, P. Koelsch, H.-L. Yip, D.S. Ginger, A.K.Y. Jen, Adv. Energy Mater. 4 (2014) 1301857.

[41] S. Torabi, F. Jahani, I. Van Severen, C. Kanimozhi, S. Patil, R.W.A. Havenith, R.C. Chiechi, L. Lutsen, D.J.M. Vanderzande, T.J. Cleij, J.C. Hummelen, L.J.A. Koster, Adv. Funct. Mater. 25 (2015) 150.

[42] X. Liu, B. Xie, C. Duan, Z. Wang, B. Fan, K. Zhang, B. Lin, F.J.M. Colberts, W. Ma, R.A.J. Janssen, F. Huang, Y. Cao, J. Mater. Chem. A 6 (2018) 395.

[43] H.-.H. Cho, S. Kim, T. Kim, V.G. Sree, S.-.H. Jin, F.S. Kim, B.J. Kim, Adv. Energy Mater. 1701436

[44] Y. Lu, Z. Xiao, Y. Yuan, H. Wu, Z. An, Y. Hou, C. Gao, J. Huang, J. Mater. Chem. C 1 (2013) 630

[45] F. Jahani, S. Torabi, R.C. Chiechi, L.J.A. Koster, J.C. Hummelen, Chem. Commun. 50 (2014) 10645.

[46] B. Carsten, J.M. Szarko, H.J. Son, W. Wang, L. Lu, F. He, B.S. Rolczynski, S.J. Lou, L.X. Chen, L. Yu, J. Am. Chem. Soc. 133 (2011) 20468.

[47] H. Zang, Y. Liang, L. Yu, B. Hu, Adv. Energy Mater. 1 (2011) 923.

[48] S.Y. Leblebici, T.L. Chen, P. Olalde-Velasco, W. Yang, B. Ma, ACS Appl. Mater. Interfaces 5 (2013) 10105.

[49] B. Bernardo, D. Cheyns, B. Verreet, R.D. Schaller, B.P. Rand, N.C. Giebink, Nat Commun. 5 (2014) 3245.

[50] T.-H. Lai, I. Constantinou, C.M. Grand, E.D. Klump, S. Baek, H.-Y. Hsu, S.-W. Tsang, K.S. Schanze, J.R. Reynolds, F. So, Chem. Mater. 28 (2016) 2433.

[51] H. Yan, Z. Chen, Y. Zheng, C. Newman, J.R. Quinn, F. Dotz, M. Kastler, A. Facchetti, Nature 457 (2009) 679.

[52] Q. Zhang, M.A. Kelly, N. Bauer, W. You, Acc. Chem. Res. 50 (2017) 2401.

[53] D. Dang, W. Chen, R. Yang, W. Zhu, W. Mammo, E. Wang, Chem. Commun. 49 (2013) 9335.

[54] K.-H. Kim, H. Kang, H.J. Kim, P.S. Kim, S.C. Yoon, B.J. Kim, Chem. Mater. 24 (2012) 2373.

[55] M.A. Uddin, Y. Kim, R. Younts, W. Lee, B. Gautam, J. Choi, C. Wang, K. Gundogdu, B.J. Kim, H.Y. Woo, Macromolecules 49 (2016) 6374.

[56] X. Guo, M. Zhang, J. Tan, S. Zhang, L. Huo, W. Hu, Y. Li, J. Hou, Adv. Mater. 24 (2012) 6536.

[57] D. Qian, W. Ma, Z. Li, X. Guo, S. Zhang, L. Ye, H. Ade, Z.A. Tan, J. Hou, J. Am. Chem. Soc. 135 (2013) 8464

[58] J. Yuan, H. Dong, M. Li, X. Huang, J. Zhong, Y. Li, W. Ma, Adv. Mater. 26 (2014) 3624

[59] C. Wang, X. Xu, W. Zhang, J. Bergqvist, Y. Xia, X. Meng, K. Bini, W. Ma, A. Yartsev, K. Vandewal, M.R. Andersson, O. Inganäs, M. Fahlman, E. Wang, Adv. Energy Mater. 6 (2016) 1600148.

[60] X. Long, Z. Ding, C. Dou, J. Liu, L. Wang, Mater. Chem. Front. 1 (2017) 852.

[61] X. Jiao, L. Ye, H. Ade, Adv. Energy Mater. 7 (2017) 1700084.

[62] W. Ma, J.R. Tumbleston, L. Ye, C. Wang, J. Hou, H. Ade, Adv. Mater. 26 (2014) 4234

[63] S. Chen, Y. An, G.K. Dutta, Y. Kim, Z.-G. Zhang, Y. Li, C. Yang, Adv. Funct. Mater. 27 (2017) 1603564.

[64] T.M. Clarke, J.R. Durrant, Chem. Rev. 110 (2010) 6736.

[65] B. Yang, J. Cox, Y. Yuan, F. Guo, J. Huang, Appl. Phys. Lett. 99 (2011) 133302.

[66] P.W.M. Blom, M.J.M. de Jong, M.G. van Munster, Phys. Rev. B 55 (1997) R656.

[67] Z. Ma, W. Sun, S. Himmelberger, K. Vandewal, Z. Tang, J. Bergqvist, A. Salleo, J.W. Andreasen, O. Inganäs, M.R. Andersson, C. Müller, F. Zhang, E. Wang, Energy Environ. Sci. 7 (2014) 361.

[68] L.J.A. Koster, M. Kemerink, M.M. Wienk, K. Maturová, R.A.J. Janssen, Adv. Mater. 23 (2011) 1670

[69] D.J. Wehenkel, K.H. Hendriks, M.M. Wienk, R.A.J. Janssen, Org. Electron. 13 (2012) 3284.

[70] C.M. Proctor, M. Kuik, T.-Q. Nguyen, Prog. Polym. Sci. 38 (2013) 1941.

[71] G. Dennler, M.C. Scharber, C.J. Brabec, Adv. Mater. 21 (2009) 1323.

[72] H. Alexander, B. Wim, G. James, S. Eric, G. Eliot, K. Rick, M. Alastair, C. Matthew, R. Bruce, P. Howard, J. Phys. Conf. Ser. 247 (2010) 012007.

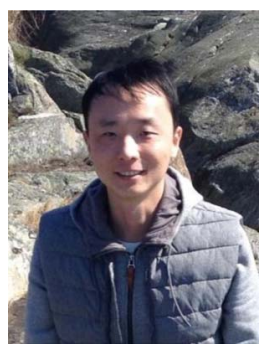

Xiaofeng $\mathrm{Xu}$ is a post doc at the Department of Chemistry and Chemical Engineering/Applied Chemistry, Chalmers University of Technology, Sweden. He obtained his Ph.D. from South China University of Technology in 2011. During 2011-2014, he worked as a post doc at School of Chemical and Biomedical Engineering, Nanyang Technological University, Singapore. His current research focuses on developing high-performance and stable all-polymer solar cells.

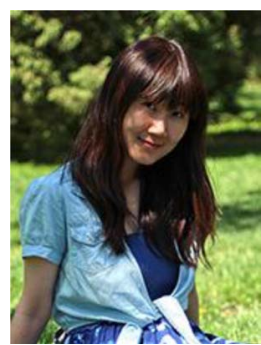

Zhaojun Li received her B.S. degree from University of Science and Technology Beijing in 2011. She received her M.S. degree from University of Science and Technology Beijing \& Institute of Chemistry of Chinese Academy of Sciences (CAS) in 2013. She is now a Ph.D. candidate in Department of Chemistry and Chemical Engineering/ Applied Chemistry, Chalmers University of Technology, Sweden. Her research focuses on design and synthesis of NIR absorbing oligomers and polymers with high absorption coefficients and high-performance all-polymer solar cells.

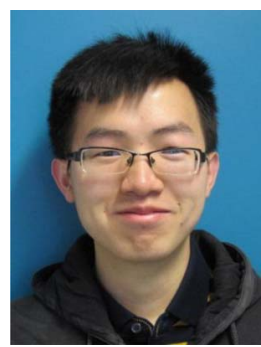

Junke Wang received his B.S. degree in Materials Science and Engineering at Central South University, China in 2013. He received his M.S. degree in Chemical Engineering at Eindhoven University of Technology in 2016. Now, he is a Ph.D. candidate in Prof. René Janssen's group. His research focuses on developing new device architectures for all solution-processed perovskite-perovskite tandem solar cells.

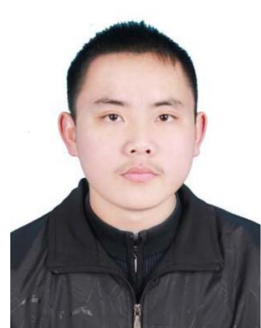

Baojun Lin received his B. Eng. degree in Materials Science \& Engineering from Xi'an JiaoTong University in 2017. Now, he is a graduate student in Prof. Wei Ma's Group at Xi'an Jiaotong University. His research focuses on characterizing the morphology of organic solar cells

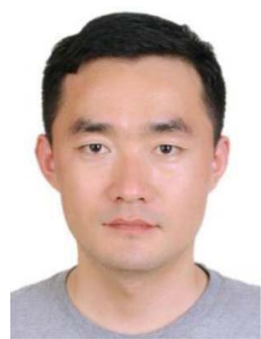

Wei Ma obtained his Ph.D. in Chemical Physics from the University of Pierre Marie Curie (Paris 6, France) in 2010 before moving to the Ecole Normale Superieure (Paris), France (2010-2011) and North Carolina State University (NCSU, 2011-2014) as a post doc. He joined the School of Materials Science Engineering at Xi'an Jiaotong University in 2014 as Professor. His research interests include the use of soft/hard X-ray based techniques to reveal the relation ship between film microstructure and device performance.

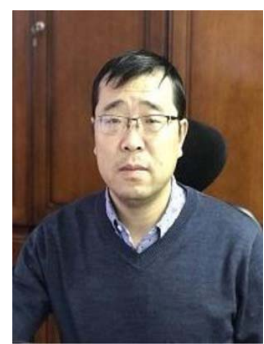

Yangjun Xia is Professor in the Key laboratory of Optoelectronic Technology and Intelligent Control of Education Ministry of China, Lanzhou Jiaotong University (LZJTU), China. He received his B.S. (2002) and Ph.D (2003) from Lanzhou University and South China University of Technology, respectively. He joined LZJTU in July 2006. His current research interests include the design and synthesis of organic/polymer optoelectronic materials for light-emitting diodes, photodetectors and photovoltaic cells. 


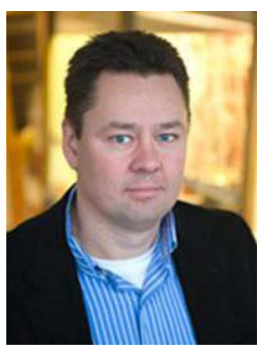

Mats R. Andersson joined Flinders University as a Matthew Flinders Fellow in 2017 and he is currently a professor and deputy director of Centre for NanoScale Science and Technology, Flinders. He received his Ph.D. in Organic Chemistry in 1995 from Chalmers University of Technology, Sweden. Mats was appointed Professor in Polymer Chemistry in 2004 and held a chair in Polymer Chemistry 2007-2015 at Chalmers University of Technology. His research interests are focused on structure-property relationships of organic materials in polymer electronics.

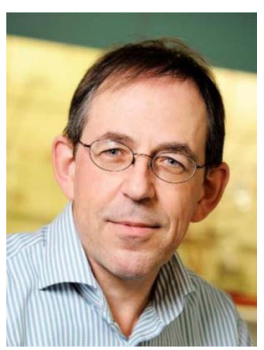

René A. J. Janssen is Professor in the Departments of Chemical Engineering \& Chemistry and Applied Physics at the Eindhoven University of Technology (TU/e). He received his Ph.D. on chemistry from TU/e in 1987. The research of his group focuses on functional conjugated molecules, macromolecules, nanostructures, and materials that may find application in advanced technological applications. Synthetic organic and polymer chemistry are combined with time-resolved optical spectroscopy, electrochemistry, morphological characterization and the preparation of prototype devices to accomplish these goals. In recent years many of the activities have concentrated on organic and hybrid solar cells.

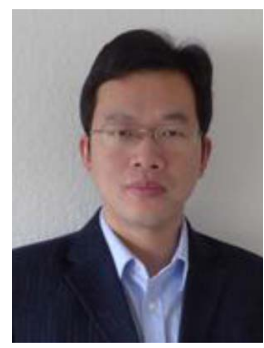

Ergang Wang obtained his Ph.D. in Materials Science in South China University of Technology in 2008. After that, he joined Chalmers University of Technology as a post doc in 2008-2011. He was appointed as an Assistant Professor in 2012 and Associate Professor in 2016 at Chalmers. He was elected as Wallenberg Academy Fellow in 2017. The focus of his work is mainly on the design and synthesis of conjugated polymers and graphene-like materials for applications in organic solar cells, organic light-emitting diodes, organic light-emitting electrochemical cells and organic field-effect transistors. 